\title{
Modeling Direction Selectivity of Simple Cells in Striate Visual Cortex within the Framework of the Canonical Microcircuit
}

\author{
Humbert Suarez,' Christof Koch, ${ }^{1}$ and Rodney Douglas ${ }^{1,2,3}$ \\ ${ }^{1}$ Computation and Neural Systems Program, California Institute of Technology, Pasadena, California 91125, ${ }^{2}$ Center \\ for Biological and Medical Systems, Imperial College of Science and Technology, London, United Kingdom, and \\ ${ }^{3}$ Institute of Neuroinformatics, Eidgenössische Technische Hochschule and University of Zürich, Switzerland
}

\begin{abstract}
Nearly all models of direction selectivity (DS) in visual cortex are based on feedforward connection schemes, where geniculate input provides all excitatory synaptic input to both pyramidal and inhibitory neurons. Feedforward inhibition then suppresses feedforward excitation for nonoptimal stimuli. Anatomically, however, the majority of asymmetric, excitatory, synaptic contacts onto cortical cells is provided by other cortical neurons, as embodied in the $\mathrm{Ca}$ nonical Microcircuit of Douglas and Martin (1991). In this view, weak geniculate input is strongly amplified in the preferred direction by the action of intracortical excitatory connections, while in the null direction inhibition reduces geniculate-induced excitation. We investigate analytically and through biologically realistic computer simulations the functioning of a cortical network based on massive excitatory, cortico-cortical feedback.

The behavior of this network is compared to physiological data as well as to the behavior of a purely feedforward model of DS based on nonlagged input. Our model explains a number of puzzling features of direction selective simple cells, including the small somatic input conductance changes that have been measured experimentally during stimulation in the null direction, and the persistence of DS while fully blocking inhibition in a single cell. Although the operation at the heart of our network is amplification, the network passes the linearity test of (Jagadeesh et al., 1993). We make specific predictions concerning the effect of selective blockade of cortical inhibition on the velocity-response curve.
\end{abstract}

[Key words: direction selectivity, simple cells, visual cortex, cortico-cortical connections, excitatory feedback, canonical microcircuit, computer modeling]

Cortical direction selectivity (DS) is usually thought to arise from a Barlow and Levick type feedforward scheme (Barlow and Levick, 1965), in which the response to the preferred direction of motion arises from the afferent input, while the response

Received Mar. 14, 1995; revised May 30, 1995; accepted June 6, 1995.

This research was supported by the Office of Naval Research, the Air Force Office of Scientific Research, the National Science Foundation, the Medical Research Council, and the Gatsby Foundation. H.S.S. was supported by NIH grant EY06264-03, a Parsons Foundation Fellowship, and an NSF Graduate Fellowship. We thank Kevan Martin, Öjvind Bernander, and Gary Holt for many fruitful discussions and their help.

Correspondence should be addressed to Prof. Christof Koch, Division of Biology, 139-74, Caltech, Pasadena, CA 91125.

Copyright C 1995 Society for Neuroscience $0270-6474 / 95 / 156700-20 \$ 05.00 / 0$ in the opposite (null) direction is suppressed by spatially offset inhibition (Bishop et al., 1971; Benevento et al., 1972; Emerson and Gerstein, 1977; Torre and Poggio, 1978; Ganz, 1984; Koch and Poggio, 1985; Ruff et al., 1987; Maex and Orban, 1991; Wörgötter and Holt, 1991; Wörgötter et al., 1992). Another class of models of direction selectivity were derived from spatio-temporal energy models of the psychophysics of motion detection (Adelson and Bergen, 1985; Watson and Ahumada, 1985). They are based on either purely linear spatio-temporal filtering (Reid et al., 1987, 1991; Hamilton et al., 1989; McLean and Palmer, 1989; Saul and Humphrey, 1990; McLean et al., 1994) or such filtering followed by an expansive nonlinearity (Albrecht and Geisler, 1991; DeAngelis et al., 1993; Heeger, 1993), and include both suppression in the null direction and facilitation in the preferred direction. In these models spatio-temporal tuning is sometimes oblained using combinations of lagged/nonlagged geniculate input (Mastronarde, 1987; Saul and Humphrey, 1990, 1992b; Emerson et al., 1992).

Variants of the first scheme are inconsistent with a number of features of cortical DS. In particular, these models fail to account for the massive excitatory interconnections seen in cortex, which numerically totally overshadow geniculo-cortical synapses. Indeed, in mammalian visual cortex, on the order of $10 \%$ of all excitatory synapses onto layer 4 cells are provided by thalamic afferent (actual estimates range from a low $2 \%$ to a high $28 \%$; S LeVay, 1976; LeVay, 1986; Douglas and Martin, 1991; Peters and Payne, 1993; Ahmed et al., 1994; Peters et al., 1994). Even such an explicit nonlinear model based on intracellular data as the one by Carandini and Heeger (1994), disregards these anatomical findings.

Both classes of models fail to explain that intracellular in vivo recordings in cat simple cells fail to detect significant changes in somatic input conductance during stimulation in the null direction (Douglas et al., 1988; Bernuan et al., 1991). In feedforward models, a large input from the direction symmetric lateral geniculate nucleus (LGN) is needed to generate the high firing rates observed during stimulation in the preferred direction. In the null direction, large inhibitory conductances changes would be needed to prevent the cell from firing to this excitatory input even in the absence of shunting inhibition. Physiological checks, assisted by simulations, have confirmed that these conductance changes should have been picked up by Douglas et al. (Koch et al., 1990; Dehay et al., 1991; Douglas and Martin, 1991; Berman et al., 1992). The remarkable lack of large inhibitory conductance changes has subsequently been reported by other laboratories (Pei et al., 1991; Ferster and Jagadeesh, 1992). 
To explain these puzzling observations, Douglas and Martin proposed the Canonical Microcircuit of neocortex (Douglas and Martin, 1990, 1991; Berman et al., 1991), which includes strong cxcitatory conncctions among cortical pyramidal and spiny stellate cells. In this scheme, only weak LGN input is needed, since in the preferred direction the cortico-cortical connections amplify the initial excitation coming from the LGN; counteracting the small LGN input in the null direction requires only weak inhibition below the detection limit of Douglas et al. (1988). In this view, Barlow-Levick inhibition in the null direction is combined with cortical amplification in the preferred direction, resulting in a direction selective cortical cell. We will call this scheme the cortical amplifier model.

Douglas and Martin (1991a) used computer simulations with continuous, mean-rate neurons to qualitatively verify some of the key concepts of their model. We report here much more realistic computer simulations of a network of excitatory and inhibitory neurons (identified as pyramidal and smooth neurons; note, however, that the excitatory neurons could also be spiny stellate cells in layer 4) and compare in detail the propertics of the cortical amplifier with those of a conventional feedforward model of DS. The cortical amplifier conforms to recent intracellular linearity tests (Jagadeesh et al., 1993), and GABAblocking experiments (Nelson et al., 1994). In our model, DS is strong and relatively independent of velocity and contrast, as observed in neurons in area 17. Several of these properties cannot be obtained with a feedforward model using nonlagged input and based on Barlow and Levick's scheme for retinal DS. We provide analytical insights into the key anatomical and physiological parameters controlling the circuit's behavior. Some of these results have appeared (Suarez et al., 1992; Douglas et al., 1995). Maex (1994) has simulated a similar model of cortical direction selectivity, with results similar to ours.

\section{Materials and Methods}

\section{Design methodology}

Our model describes events occurring in a small network of simple cells located in the primary visual cortex of the adult cat. For simplicity of implementation, only the ON portion of the $\mathrm{X}$ pathway is modeled (Lennie, 1980; Sherman, 1985). Given the immense wealth of available experimental data on area 17 at the biophysical, analonical and physiological level, and the large computational cost associated with simulating realistic cortical network models, we adopted the following design criteria in order to obtain results within a realistic time-frame. These included the following.

(1) Our desire to obtain the proper intracellular voltage dynamics and conductance changes forced us to use a realistic single-cell model that includes action potentials within a Hodgkin and Hodgkin framework. This, more than anything else, results in tremendous computational costs, given the small time-steps necessary for stable solution of the underlying differential equations. We are less concerned with the exact details of which membrane conductance has what type of kinetics and is located in what type of compartment. In our experience, this is not that relevant for the overall network dynamics operating at the 50$100 \mathrm{msec}$ scale (Wehmeier et al., 1989; Wörgötter and Koch, 1991).

(2) Given this cost, as well as the large number (about 140) of cellular and network parameters associated with our model, it is simply not feasible to characterize its sensitivity to variations in parameters. The simulations reported here-all based on a single parameter setting-should be taken as proof-of-concept that a massive cortical feedback excitation can in principle explain a number of otherwise puzzling anatomical and physiological observations. We then try to analyze a simplified model of the network to understand its key operations.

(3) We restricted ourselves to replicating a small number of experimental findings relevant to our purposes. These were (1) direction-selectivity, velocity-/and contrast-tuning over a wide range, (2) certain linearity constraints, (3) the biophysics of conductance changes, and (4) the effect of blocking inhibition. In this article, we do not consider a number of important phenomena such as the contribution of lagged geniculate cells to direction selectivity (Mastronarde, 1987; Saul and Humphrey, 1990, 1992b; Emerson et al., 1992), orientation, color or disparity selectivity, end-stopping, ON as well as OFF input, and Cartesian nonseparability of simple receptive fields (Jones and Palmer, 1987a,b; Reid et al., 1991; McLean et al., 1994).

(4) Given this high dimensional parameter space, the poverty of our single cell model and the observed variability of single cell responses to visual stimuli, we can not reproduce the observed response curves quantitatively. Our goal was for our network to show proportional responses within the known range of firing rates.

We hope in future extensions of this work to tackle and possibly eliminate a number of these-at the moment—unavoidable simplifications and constraints.

\section{Visual input}

Visual input to the network is provided by a one-dimensional retinogeniculate module, transforming a given input, usually a moving bar or grating, into a series of spikes mimicking the output of the geniculate relay cells (Victor, 1987). Direction selectivity is strongest in the direction orthogonal to the preferred orientation of cells in area 17, and for simplicity our model is restricted to this one spatial dimension.

Visual stimuli. Visual stimuli are provided to the model as 1-D pixel frames (see Fig. 3) with $1^{\prime}$ per pixel resolution and an effective frame rate of $10 \mathrm{kHz}$. The amplitude at each pixel corresponds to the fractional deviation from the mean luminance. Moving bar stimuli were modeled by a group of same-valued pixels, moving at a constant velocity. Drifting sine wave gratings were modeled by moving patterns of pixel values that are modulated sinusoidally over space, and contrast-reversal stationary gratings by patterns of pixel values with separable spatial and tcmporal sinusoidal modulations. We give here the definition of stimulus contrast used in this article. For a bar, it is the Weber contrast:

$$
C=100 \frac{L-L_{b}}{L_{b}}
$$

where $L$ is the luminance of the bar and $L_{b}$ is the luminance of the background. For a moving grating, we use the Rayleigh-Michelson contrast:

$$
C=100 \frac{L_{\max }-L_{\min }}{L_{\max }+L_{\min }}
$$

where $L_{\max }$ and $L_{\min }$ are the maximum and minimum luminance in the pattern.

Retino-geniculate module. The dynamics of the geniculate input to striate cortex needs to be modeled with some care, because the timing of geniculate input is critical for direction selectivity, and because the velocity-response curves of our model cortical neurons are only meaningful if the velocity-response curve of the geniculate input is accurate. Beyond these considerations, the detailed properties of the retinal and geniculate cells are not central to our simulations.

The response to visual stimulation of ON geniculate relay cells of the $\mathrm{X}$ type is computed as a transfer function. As in Wehmeier et al. (1989), we model a patch of retinal cells located $1 \mathrm{~mm}$ away from the area centralis, or about $4.5^{\circ}$ eccentricity. Receptive fields at that eccentricity have a difference of Gaussians, center-surround type of receptive field (Rodieck, 1965; Enroth-Cugell and Robson, 1966; Linsenmeier et al., 1982; Enroth-Cugell et al., 1983; see Fig. 1a) with a center diameter of approximately $30^{\prime}$ (Fig. 1c; Pcichl and Waessle, 1979, Linsenmeier et al., 1982). The cells respond to a light stimulus by a transiently high discharge rate that adapts to a maintained level (Fig. 1d). We used Victor's model (1987) of the center component of retinal X cells to simulate the temporal properties of our geniculate cells (Fig. 1b). The Victor model postulates a series of low-pass filters followed by a highpass filter and some nonlinear processing at high contrast values. For reasons of computational efficiency, we used identical temporal filters for both center and surround, neglecting differences in their dynamics (Dawis et al., 1984). Following Victor's model, the surround's response was substracted from the center's. The output of a model LGN cell is technically speaking not separable in time and space, because of a small temporal delay $(3 \mathrm{msec}$ ) we introduced between the center and the surround response, consistent with experimental observations (Enroth-Cugell et al., 1983). The continuous output of this filtering stage determines the instantaneous rate of a Poisson process that generates discrete 


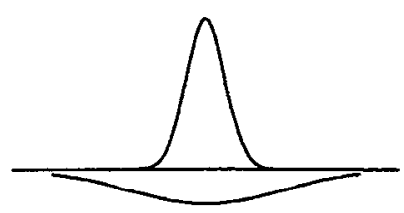

Figure 1. Basic characteristics of the LGN model. $a$, Spatial filters for the center and surround, modulating the responses to a thin bar (shown here with $1^{\prime}$ width in the center of the receptive field). The $\sigma$ of the Gaussians is $6^{\prime}$ for the center, and $24^{\prime}$ for the surround. $b$, The impulse responses of the center and surround (to an impulse lasting 1 msec), summarizing the action of their temporal filters. $c$, The sustained average response of a LGN neuron, in impulses/sec, to a thin bar ( $1^{\prime}$ width, $100 \%$ contrast). $d$, Our geniculate cells respond to input with Poisson distributed spikes whose rate is modulated by the visual stimulus (superimposed onto a spontaneous firing activity of $8 \mathrm{~Hz}$ ). We here show the mean rate of one LGN cell (in the form of a poststimulus time histogram, PSTH) in responsc to 1600 presentations of a thin bar $\left(1^{\prime}\right.$ width, $100 \%$ contrast) at the center of its receptive field. (c)

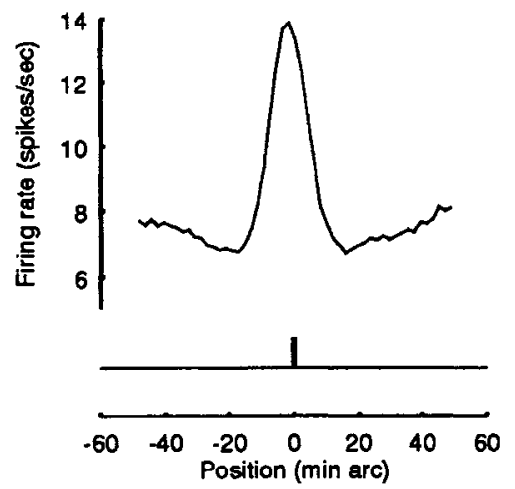

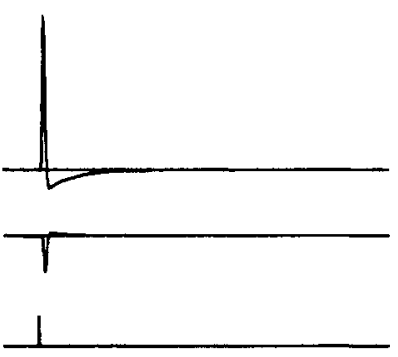

(d)

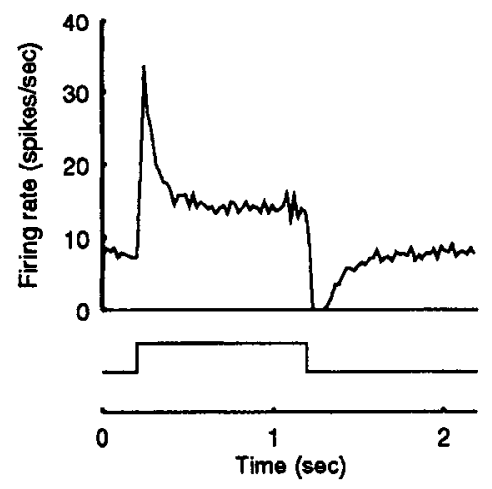

impulses (spikes). We superimpose a spontaneous firing frequency of 8 $\mathrm{Hz}$ onto the stimulus-dependent response (Fig. $1 d$ ). For a $70 \%$ contrast bar moving at $10 \% \mathrm{sec}$, peak firing rates are around $140 \mathrm{~Hz}$ (see Fig. 8).

We used slightly different parameters values from Victor's (1987) retinal model, because of the different response amplitudes of LGN neurons (Bullier and Norton, 1979; Cleland and Lee, 1985; Kaplan et al., 1987). Additional contrast nonlinearities present in the LGN itself are probably insignificant in the context of our simulations, and were not included in the model (Kaplan et al., 1987).

Only responses of the $X$ pathway were simulated, because it accounts for most thalamic inputs to area 17 (Sherman, 1985; Ferster, 1989). Furthermore, since cortical direction selectivity does not require any significant interaction between the ON and OFF subsystems (Schiller, 1982, 1992; Sherk and Horton, 1984), only responses of geniculate ON $\mathrm{X}$ neurons were simulated.

Spatially, the centers of the LGN neurons' receptive fields are positioned at one of six spatial locations which occur at $5^{\prime}$ intervals (Wörgötter and Koch, 1991). To ensure that each cortical neuron receives input from a realistic number of LGN neurons, the LGN array is twodimensional: there are $13 \mathrm{LGN}$ neurons at each of the six spatial positions (a $6 \times 13$ array). Within each group of 13 cells, the one-dimensional spatial receptive fields are identical. Pyramidal neurons in cortex reccive input from the first five groups of LGN neurons, and smooth neurons receive input from the last five groups of LGN neurons (see Fig. 3). Overall, there is a spatial offset of $5^{\prime}$ between input fields of pyramidal and smooth neurons, providing the spatial asymmetry necessary for direction selectivity. Rather than connecting all 65 LGN cells to each cortical neuron, each geniculate afferent connects with a $30 \%$ probability to a given cortical neuron, so that on the average a cortical neuron receives input from $0.3 \cdot 5 \cdot 13=19.5 \mathrm{LGN}$ cells. While this number is low in comparison to estimates from experimental data (Tanaka, 1983; Freund et al., 1985a,b; Peters and Payne, 1993; Peters et al., 1994), it is adequate when one considers that the model simulates only one subfield of cortical neurons and only geniculate $\mathrm{ON}$ afferents.

\section{Pyramidal cells}

Given our aim of reconciling certain biophysical aspects of cortical cells with their response to visual stimuli, we need to incorporate the follow- ing neuronal properties into our single cell models: (1) discrete action potentials, (2) realistic time constants, (3) firing rate adaptation (in pyramidal cells only), and (4) synaptic-induced conductance changes with synaptic reversal potentials. Accordingly, we adapted the following compromise between continuous Hopfield neurons and detailed biophysical models with hundreds of compartments (Douglas and Martin, 1991; Bernander, 1993; Bush and Sejnowski, 1993).

The original model of the pyramidal cell was adapted from our anatomical and biophysical detailed model of a layer 5 pyramidal ccl (Bernander, 1983; Douglas et al., 1991) to mimick layer 4 pyramidal cells. Each neuron consists of a somatic compartment and three cylindrical compartments that represent the dendritic arbor. Each dendritic compartment is assigned a leak conductance $\left(R_{m}=10,000 \Omega \mathrm{cm}^{2}\right)$ and a particular profile of synaptically mediated membrane conductances (Fig. 2a). The soma contains five voltage-dependent ionic conductances that are modeled using Hodgkin-Huxley-like kinetics with voltage-independent time constants (Bernander et al., 1991; Bush and Douglas, 1991). The currents are a transient sodium and a delayed rectifier potassium current that underlie action potentials; a high-threshold calcium current, $I_{\mathrm{C}_{\mathrm{a}}}$, and a calcium-dependent potassium current, $I_{\mathrm{AHP}}$, and for the cortical amplifier model, a transient, A-like potassium current, $I_{\mathrm{A}}$. $I_{\mathrm{C} x}$ and $I_{\mathrm{AHP}}$ mediate the rapid (time constant $25-50 \mathrm{msec}$ ) adaptation seen in regular firing pyramidal cells (McCormick ct al., 1985). After increasing during an action potential, intracellular calcium (in the somatic compartment) decays exponentially with a time constant of 50 msec. This simplified cell's current-discharge curves (see section 3.6) are very similar to those of a substantially more complex pyramidal cell model that uses more than 300 compartments (Bernander et al. 1991).

At rest, the somatic input resistance, time constant and membrane potential of our pyramidal cells are $27.2 \mathrm{M} \Omega 7.75 \mathrm{msec}$, and -66.5 $\mathrm{mV}$ in the feedforward case, and $52.9 \mathrm{M} \Omega 22.5 \mathrm{msec}$, and $-54.2 \mathrm{mV}$ for the cortical amplifier model. The input resistance is much smaller in the feedforward than in the feedback case, since the LGN to pyramid synaptic weight is much larger (see Table 1) and therefore also the synaptic background activity from the LGN. A larger input conductance also implies a smaller membrane time constant. The resting membrane potential is related to the neuron's threshold. The neuron's threshold, 


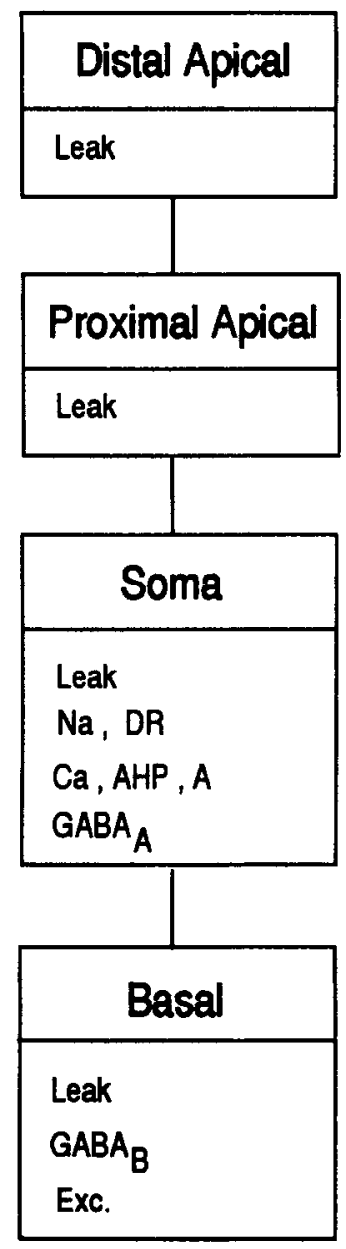

\section{(a) Pyramidal}

\section{(b) Inhibitory}

Figure 2. Compartmental models of the pyramidal and smooth neurons. Each compartment includes a number of membrane currents shown in the diagram. Not shown are the capacitances and axial resistances within and between each compartment. $a$. Pyramidal cells each have four compartments, corresponding anatomically to the basal dendritic, somatic, proximal, and distal apical dendritic compartments. $b$, Smooth GABAergic interneurons each have three compartments, for the somatic, proximal, and distal dendritic compartments. Leak, leak conductance; $\mathrm{Na}$, transient sodium current; $\mathrm{Ca}$, calcium current; $D R$, delayed rectifier $\mathrm{K}$ current; $A H P$, calcium-dependent $\mathrm{K}$ current; $A$, transient, inactivating $\mathrm{K}$ current; $F x$.., synaptic excitatory current (from geniculo-cortical and cortico-cortical afferents).

together with synaptic inhibition, contributes to direction selectivity; even if some LGN input is not cancelled by overlapping inhibition in the null direction it will not result in any response as long as it remains subthreshold. Since the LGN weight is larger in the feedforward case, the pyramidal neuron's threshold has to be larger too.

\section{Smooth cells}

The smaller, smooth, GABAergic stellate cells are modeled by removing the basal compartment from our pyramidal cell model (Fig. $2 b$ ) and adjusting the size parameters for the remaining compartments (Douglas and Martin, 1991). $I_{\mathrm{Ca}}, I_{\mathrm{AHP}}$, and $I_{\mathrm{A}}$ were also removed to enable these cells to fire at high sustained rates without showing any adaptation, in agreement with intracellular data (McCormick et al., 1985). Smooth cell parameters are identical in the feedforward and cortical amplifier models; at rest, the input resistance, time constant, and membrane potential of these cells are $65.2 \mathrm{M} \Omega 11.4 \mathrm{mscc}$, and $-56.0 \mathrm{mV}$. Compared to the cortical amplifier's pyramidal cells, despite the larger resting LGN
Table 1. Synaptic connectivity of our cortical module for the feedforward and cortical amplifier models.

\begin{tabular}{|c|c|c|c|c|c|c|c|}
\hline \multirow[b]{2}{*}{ From } & \multirow[b]{2}{*}{ To } & \multicolumn{2}{|c|}{$\begin{array}{l}\text { Connection } \\
\text { strength }\end{array}$} & \multicolumn{2}{|c|}{$\begin{array}{l}\text { Peak } \\
\text { conductance }\end{array}$} & \multicolumn{2}{|c|}{$\begin{array}{l}\text { Time } \\
\text { constants }\end{array}$} \\
\hline & & $\begin{array}{l}\text { Pyra- } \\
\text { midal }\end{array}$ & Smooth & $\begin{array}{l}\text { Pyra- } \\
\text { midal }\end{array}$ & Smooth & $\tau_{1}$ & $\tau_{2}$ \\
\hline \multicolumn{8}{|l|}{ Feedforward } \\
\hline LGN & & 38.9 & 10.8 & 8.65 & 2.40 & 4.5 & 1.8 \\
\hline Pyramidal & & - & - & - & 一 & & \\
\hline Smooth $\mathrm{GABA}_{\mathrm{A}}$ & & 45.1 & 0.39 & 4.51 & 0.039 & 10 & \\
\hline Smooth GABA & & 33.7 & 3.35 & 0.211 & 0.021 & 80 & 40 \\
\hline \multicolumn{8}{|l|}{ Amplifier } \\
\hline LGN & & 2.59 & 10.8 & 0.576 & 2.40 & 4.5 & 1.8 \\
\hline Pyramidal & & 3.38 & - & 0.169 & - & 20 & \\
\hline Smooth GABA & & 3.34 & 0.39 & 0.334 & 0.039 & 10 & \\
\hline Smooth GABA $A_{B}$ & & 2.50 & 3.35 & 0.016 & 0.021 & 80 & 40 \\
\hline
\end{tabular}

Connections are between all members of the cell types involved. The connection strength between two neurons is expressed in terms of the temporal integral over the postsynaptic conductance increase in response to a single presynaptic action potential, that is, $J g(t) d t$, in units of $\mathrm{pS} \cdot \mathrm{sec}$. The peak conductance (nS), and the synaptic time constants, $\tau_{1}$ and $\tau_{2}$ (in msec; see Eq. 3 and 4 ) are also given. The reversal potentials were $0 \mathrm{mV}$ for all excitatory synapses, $-75 \mathrm{mV}$ for $\mathrm{GABA}_{\mathrm{A}}$ and $-90 \mathrm{mV}$ for $\mathrm{GABA}_{\mathrm{B}}$ synapses. All simulations in this article were carried out with the same set of parameters.

input (because of the larger LGN weight; see Table 1), the input resistance is larger because of the smaller membrane area. The short time constant reflects the effect of the large geniculate background activity.

\section{Network connectivity}

A connection diagram of the cortical amplifier network is shown in Figure 3. It comprises 40 pyramidal and 10 smooth neurons, respecting the known proportions of cortical neurons (Winfield et al., 1980; Beaulieu and Colonnier, 1983; Hamos et al., 1983; Gabbott and Somogyi, 1986; Peters and Payne, 1993). The connections between neurons reflect the connectivity of the canonical microcircuit with the exception that the pyramidal neurons do not connect to the inhibitory neurons. This lack of feedback inhibition in our current model substantially simplified our simulations.

Each cortical connection drawn in Figure 3 symbolizes synapses of cqual strength from cach ncuron of one group to all neurons of the other group. Inhibition is of two types, $\mathrm{GABA}_{\mathrm{A}}$, or transient, and GA$\mathrm{BA}_{\mathrm{B}}$, or sustained inhibition. As explained above, the LGN inputs to the smooth neurons are spatially displaced from those to the pyramidal neurons. Local inactivation experiments using GABA microiontophoresis provide some support for the presence of a spatial displacement between smooth neurons and the direction-selective pyramidal neurons that they inhibit (Eysel et al., 1988).

For the feedforward model, the connection diagram is similar to Figure 3, except that there are no excitatory cortico-cortical connections, implementing a Barlow-Levick scheme for direction selectivity (Barlow and Levick, 1965); the connection weights are different, as we will see below.

Because excitatory and inhibitory synaptic inputs change the local mombrane conductance to a certain ion or ions, massive synaptic input is expected to have a dramatic effect on a cell's spatio-temporal structure, in particular on the input resistance and time constants (Bernander et al., 1991; Rapp et al., 1992). Therefore, it is important to explicitly model synaptic input as conductance change (in series with a battery), rather than a simple current injection, as common in nearly all neural network models.

The amplitudes of synaptic conductances and time constants that govern their behavior have yet to be determined experimentally in detail for pyramidal and spiny stellate cells in primary visual cortex (see also Bernander, 1993). However, there are estimates from the literature that can be used for constraining our model. This data is usually based on in vitro cortical preparations (Tanaka, 1983; Connors et al., 1988; Thomson et al., 1988; Busch and Sakmann, 1990; Edwards et al., 1990; Kricgstcin and LoTorco, 1990; LaCaillc, 1991; Lytton and Sejnowski, 1991; Mason et al., 1991; Williams and Johnston, 1991). 
Figure 3. Connectivity diagram of the direction selectivity model. Input to LGN neurons comes from an onedimensional array of retinal pixels. The intensities from those pixels are summed through difference-of-Gaussians spatial filters onto LGN neurons, with a spatially offset filter at each position. six spatial positions. The LGN neurons connect slightly differently with the two populations of cortical neurons, so that as a group the LGN inputs to the pyramids are spatially offset by $5^{\prime}$ with respect to those to the smooth neurons $(\Sigma$ indicates convergence of the geniculate inputs onto cortical neurons). Each geniculate cell independently has a $30 \%$ probability of making a synapse with its appropriate cortical target (see Materials and Methods). The open triangle symbols denote excitatory con$\mathrm{GABA}_{\mathrm{A}}$ connections, and the solid circles inhibitory $\mathrm{GABA}_{\mathrm{B}}$ connections. There are 13 LGN neurons at each of nections, the solid triangles inhibitory

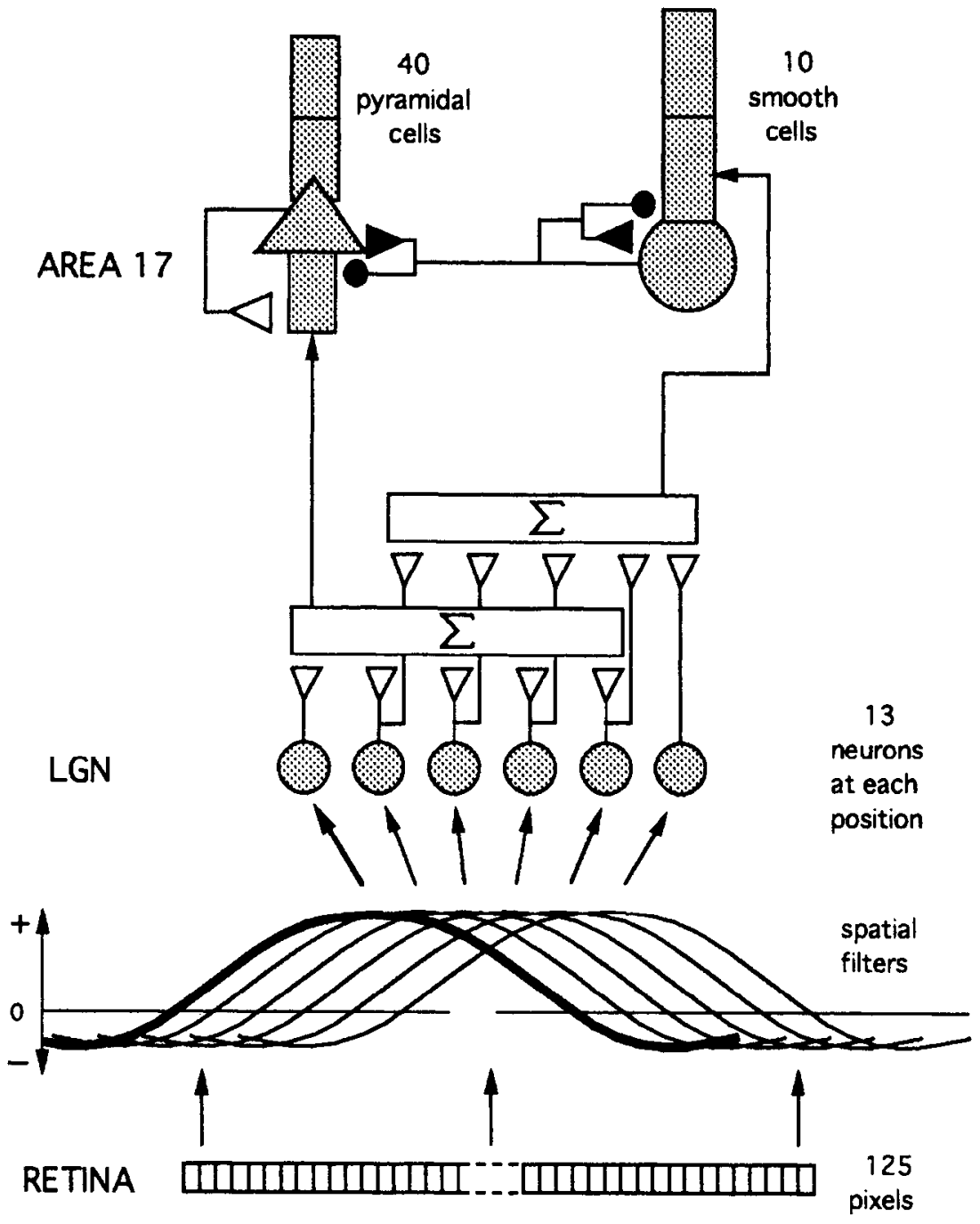

In the model, the excitatory postsynaptic currents arise exclusively from fast, voltage-independent non-NMDA or AMPA synapses located in the proximal dendritic compartment (Fig. 2). Voltage-dependent NMDA synaptic inputs are not included in the current version of our model (see Discussion). However, because we wanted to retain the slower dynamics of the NMDA receptor, we adopt the compromise of using voltage-independent excitatory synaptic input with a decay of 20 msec rather than the few milliseconds appropriate for a pure AMPA synapse. A second reason for using a $20 \mathrm{msec}$ decaying input is to compensate for the lack of distal dendritic compartments. The associated low-pass filtering will lead to a broadening of the synaptic current flowing into the soma.

Two types of inhibitory postsynaptic currents are included: fast, shunting, chloride based GABA ${ }_{A}$ inhibitory synapses are located in the somatic compartment, while slow, hyperpolarizing, potassium based $\mathrm{GABA}_{\mathrm{B}}$ inhibitory synapses are located in the dendritic compartments (Connors et al., 1988; Douglas and Martin, 1991).

The time course of the geniculo-contical and $\mathrm{GABA}_{\mathrm{B}}$ synaptic conductance change was a dual exponential (Wilson and Bower, 1989),

$$
G(t)=e^{-t / \tau_{1}}-e^{-t / \tau_{2}},
$$

while that for the excitatory cortico-cortical synapse and the GABA mediated response was a single exponential,

$$
G(t)=e^{-t / \tau_{1}} .
$$

Final synaptic parameter values are shown in Table 1. For the cortical amplifier case, each connection's strength is in the range of individual synaptic contacts, while for the feedforward model some connections would be in the upper range for individual synaptic contacts; instead, they may correspond to several synaptic contacts. For the cortical am- plifier, the LGN-to-pyramidal weight was set so as to give a slightly suprathreshold excitation for low contrast values. The smooth-to-pyramidal $\mathrm{GABA}_{\mathrm{A}}$ and $\mathrm{GABA}_{\mathrm{B}}$ weights were just large enough to balance out the LGN excitation in the null direction over a range of velocities. The setting of the pyramidal-to-pyramidal weight was high enough to obtain peak firing rates that were compatible with experimental values (Orban et al., 1981a), but low enough to still have proportional amplification (Suarez, 1995). For the feedforward model, the LGN-to-pyramidal weight was large enough to enable model neurons to fire at physiological rates despite the strong delayed inhibition. Inhibitory connections were set according to the same criterion as in the cortical amplifier.

Noise. Two external noise sources provide trial-to-trial variability. Firstly, the geniculate input itself consists of Poisson distributed spikes generated by the retino-geniculate module (see above). Superimposed onto the stimulus driven geniculate response is a spontaneous firing activity of $8 \mathrm{~Hz}$ (Fig. 1d). Since the LGN weight is larger in the feedforward model than in the cortical amplifier model, the fluctuations in the resting somatic membrane potential are higher in the former case.

Secondly, some background noise is added to both pyramidal and smooth model neurons to simulate the effect of spontaneous activity in the numerous cortical neurons outside our network. Noise events are modeled either as conductance changes or as current injections. Parameters of each conductance change or current injection function are set so as to model inhibitory $\left(\mathrm{GABA}_{\mathrm{A}}\right.$ or $\left.\mathrm{GABA}_{\mathrm{B}}\right)$ or excitatory nonNMDA synaptic inputs; the locations are the same as for these inputs. In the pyramidal neurons, we assume that $44 \%$ of the noise originates from current injections and the rest from spontaneous conductance increases. There were only conductance increases in the smooth neurons.

For the feedforward model, the spontaneous firing frequency of the pyramidal and smooth cells is $0.046 \pm 0.009 \mathrm{~Hz}$ and $8.2 \pm 0.2 \mathrm{~Hz}$, 
while for the cortical amplifier model those values are $1.56 \pm 0.02 \mathrm{~Hz}$ and $8.1 \pm 0.1 \mathrm{~Hz}$. Because we wanted to obtain good direction selectivity down to low contrast and low velocities, the threshold of the pyramidal neurons was higher than that of the smooth neurons, which explains the lower spontaneous rate of the pyramidal cells.

\section{Computer implementation}

The simulations were carried out on UNIX-based workstations. The program, written in C, was developed by H.S. as part of his Ph.D. thesis. The associated differential equations were numerically solved using the exponential method (Wilson and Bower, 1989) with a variable timestep (Press et al., 1992). The shortest time constant in the system was 0.05 msec, the activation time constant of the transient sodium current. The minimum time step for solving the differential equations was set to 0.01 msec. On a SPARCstation 10, our program simulated $1 \mathrm{sec}$ of model output for a moving bar in about $404 \mathrm{sec}$, not counting the time to simulate the visual input and LGN model output.

\section{Data analysis}

Standard electrophysiological methods were used for data analyses.

Contrast-response and velocity-response curves. Contrast-response curves were obtained from sine wave gratings moving in the preferred direction with optimum spatial and temporal frequency $(1 \mathrm{c} / \mathrm{deg}$ and 1 $\mathrm{Hz}$ ), repeated for 26 cycles. Velocity-response curves were obtained from $0.5^{\circ}$ wide bars moving in the preferred direction with high enough contrast to elicit a strong response ( $70 \%$ contrast), repeated six times with a half-second pause between each presentation. The response measure used was the peak response, computed from $8 \mathrm{msec}$ binwidth poststimulus time histograms (PSTHs). Usually PSTHs were summed over all neurons of one group (pyramidal or smooth) to generate a compound (average) PSTH. The compound peak firing rate was computed from the compound PSTH as the highest bin in the histogram.

Direction index. The direction index $(D I)$ was computed from the compound peak firing rate in the preferred direction, minus the peak spontaneous firing rate $(P)$, and the compound peak firing rate in the nonpreferred direction, minus the peak spontaneous firing rate $(N P)$ :

$$
D I=100(1-N P / P) \%
$$

Since the spontaneous firing rate is substracted to obtain $P$ and $N P, D I$ may be larger than $100 \%$ if the peak firing rate in the nonpreferred direction is smaller than the peak spontaneous rate.

The Mean Direction Index (MDI) is a velocity-averaged direction index. The average is weighted by the response $P_{i}$ in the preferred direction (Orban, 1984):

$$
M D I=\frac{\sum_{i=1}^{n} P_{i} D I_{i}}{\sum_{i=1}^{n} P_{i}}
$$

where $n$ is the number of velocities for which the direction index has been computed.

Blocking GABA. Blocking $\mathrm{GABA}_{\mathrm{A}}$ and $\mathrm{GABA}_{\mathrm{B}}$ inhibition to all or to one particular pyramidal neuron in the model is done by simply setting the corresponding weight to 0 .

In one experiment, we blocked inhibition to only one pyramidal neuron in the model, and measured the direction selectivity index of that neuron before and after blockade. The experiment was repeated for every pyramidal neuron in the model; the results were presented as histograms of the distribution of the neurons' direction indices before and after blockade, mimicking an experiment in cat area 17 (Nelson et al., 1994). The stimulus was a standard bar (70\% contrast and moving at $2 \% \mathrm{sec}$ ) that was repeated six times, and the response measure was the average number of spikes produced by a neuron while the stimulus is in the neuron's receptive field, corrected for the mean spontaneous rate. The mean spontaneous firing rate of pyramidal cells in the cortical amplifier was $1.56 \mathrm{~Hz}$. While blocking inhibition in a given cell, a constant hyperpolarizing current was injected into the cell to bring spontaneous firing down to values close to the unblocked case. The same manipulation was performed by (Nelson et al., 1994) to ensure that the neuron's threshold was not changed by blocking inhibition.

\section{Results}

\section{Basic performance}

The salient features of the cortical amplifier model's performance can be seen in Figure 4 in response to the presentation of a bar moving in the preferred (left-to-right direction on Fig. 3) and null directions. The pyramidal cell population is strongly direction-selective: generating a burst of spikes in the preferred direction, but no or only a few spikes in the null direction (given a spontaneous activity of $1.5 \mathrm{~Hz}$, we expect three spikes to occur during this $2 \mathrm{sec}$ period); thus, the smooth-to-pyramidal weight is large enough relative to the LGN-to-pyramidal weight so that the inhibition completely cancels LGN excitation in the null direction.

In the preferred direction, the pyramidal neurons stop firing before the stimulus leaves their receptive field, because of inhibitory input from the smooth neurons, combined with the effect of high threshold and the calcium-dependent firing adaptation. Thus, pronounced firing in the pyramidal cells is followed by pronounced hyperpolarization, as observed in intracellular recordings from cat visual cortex (Benevento et al., 1972; Creutzfeldt et al., 1974; Ferster, 1988; Douglas et al., 1991). In turn, the smooth neurons are suppressed when the stimulus enters their LGN neurons' surrounds. Subsequently, some discharge occurs due to rebound as the stimulus leaves the surrounds. There is little late discharge in the pyramidal neurons because they have a higher threshold.

In the null direction, the smooth cells receive LGN input before the pyramidal neurons because the LGN input to the smooth cells is spatially displaced with respect to that of the pyramidal cells: the spatial offset is $5^{\prime}$ and the bar speed is $2 \%$ sec, corresponding to a delay of about $42 \mathrm{msec}$. This spatial offset is in our model the primary cause of direction selectivity. Because the small required weight of the smooth-to-pyramidal synapse, the cortical amplifier feedback model shows only moderate hyperpolarization (Fig. 4d), as observed in the recordings from cat cortex. Indeed, the smooth-to-pyramidal weight is relatively small. In contrast, the hyperpolarization in the feed-forward model in the null direction is much deeper, due to the larger inhibition required to cancel the excitatory current (not shown).

Iligh signal amplification is achieved within the canonical microcircuit. Figure $5 a$ compares the excitatory recurrent current to a pyramidal cell with the excitatory current induced by the LGN afferents for a bar moving in the preferred direction. Clearly, the dominating excitatory input during response originates from other cortical neurons rather than the LGN. The LGN-topyramidal synaptic weight is small; nevertheless, the pyramidal neurons discharge strongly because of the current contributed by the connections between the pyramidal neurons. However, the LGN current is not the input signal being amplified by the network of pyramidal neurons. Instead, the total input signal to the pyramidal neurons is the LGN input current minus the total inhibitory current contributed by all smooth neurons: the net input current. This current is shown together with the LGN current in Figure $5 b$, for the same stimulus as Figure $5 a$. Initially, the net input current is positive because in the preferred direction the LGN current precedes the inhibitory current. Then, the inhibitory current becomes larger than the LGN's, so the net current becomes negative. Eventually, the inhibitory current decays, as the stimulus leaves the receptive field of the inhibitory neurons. The real amplification factor achieved by the canonical microcircuit is much larger than suggested in Figure $5 a$ : it is about 4.7 in Figure $5 b$.

Finally, because of the weak geniculate input that only requires relatively little inhibition to suppress it below the firing threshold, pyramidal cells in the canonical amplifier show a maximal increase in their somatic input conductance of $60 \%$ 


\section{Raster plot}

\section{Preferred}

(a)

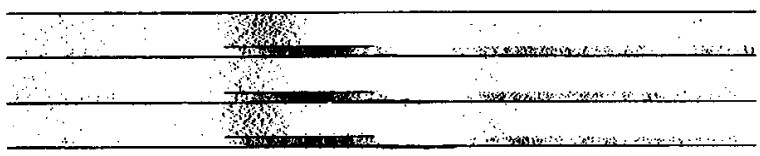

Null

(c)

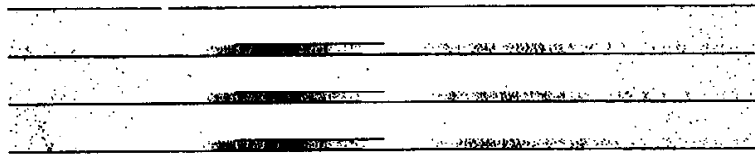

$-100 \mathrm{msec}$

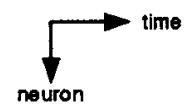

(b)

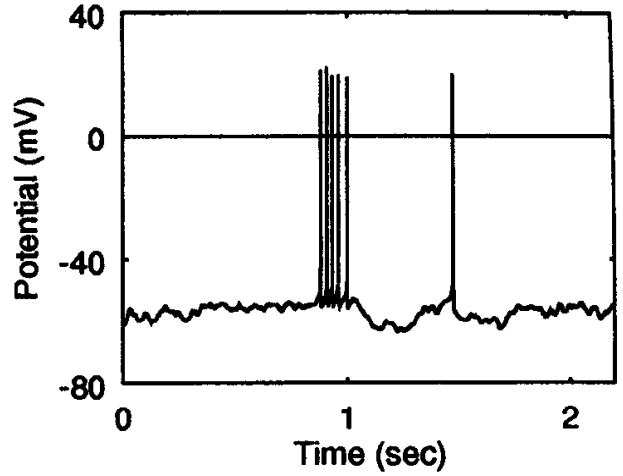

(d)

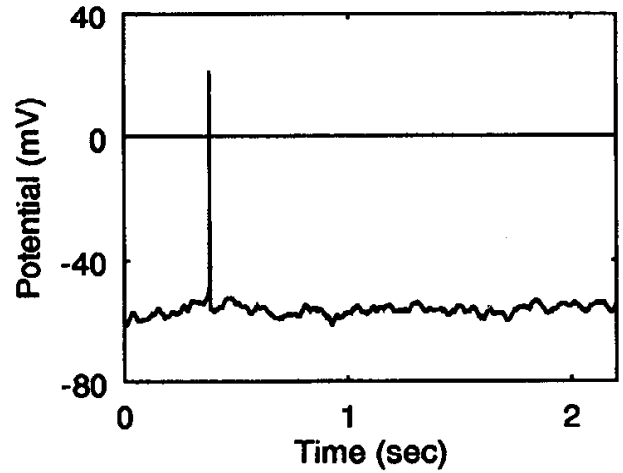

Figure 4. Basic performance of the cortical amplifier. Response of the pyramidal and smooth neuron population to a $70 \%$ contrast bar moving at $2 \% \mathrm{sec}$ in $(a, b)$ the preferred and $(c, d)$ the null direction of motion. The raster plots show three trials, while the somatic potential is shown for a single one. The first 40 rows in each raster trace indicate spiking activity in the pyramidal cells. The continuous bar just below these rows indicates when the stimulus is within the receptive fields of the LGN inputs to the pyramidal cells. The 10 rows below the bar correspond to firing activity in the 10 interneurons. Note the strong direction selectivity of the pyramidal neurons, whereas the smooth neurons are not direction selective. However, this is not an essential feature of our model. The spontaneous activity in the interneurons is approximately five times higher than the spontaneous activity in the pyramidal cells.

a)

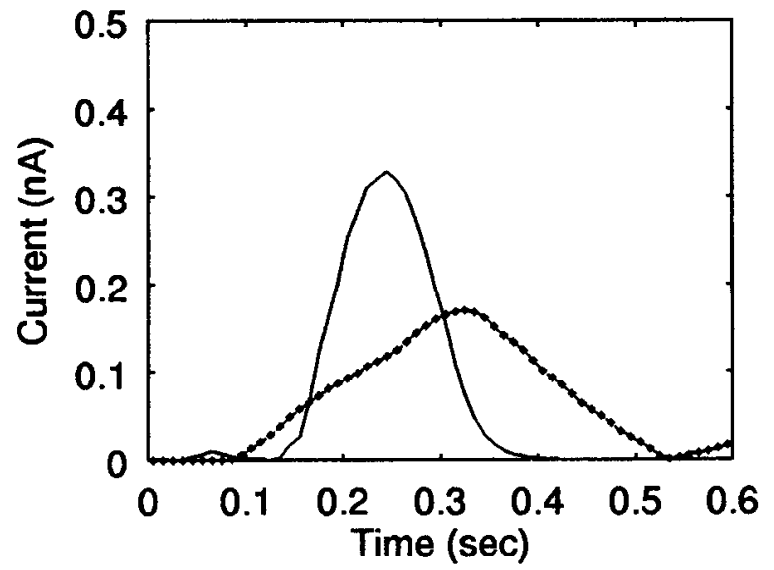

b)

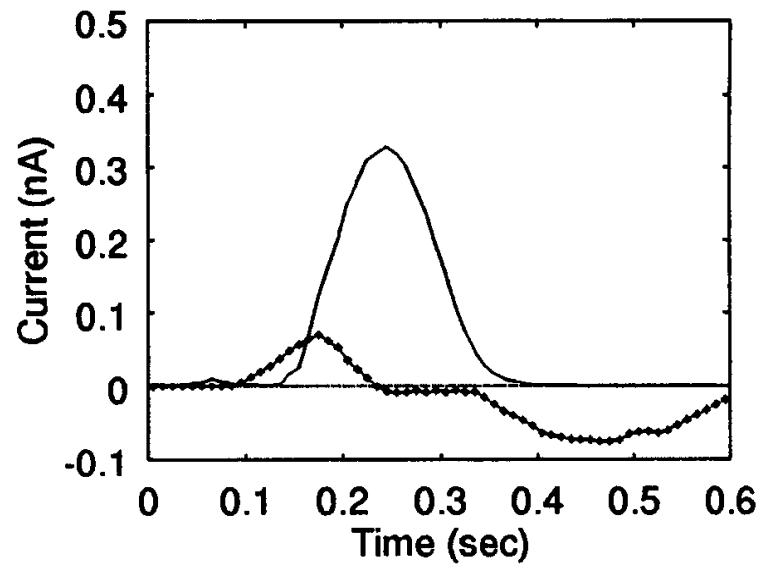

Figure 5. Current amplification in the preferred direction in the cortical amplifier. a, Excitatory cortico-cortical current (solid line) compared to that arriving from the LGN afferents (dotted bold line), for a pyramidal neuron of the cortical amplifier model during stimulation by a $70 \%$ contrast bar moving at $2 \% \mathrm{sec}$ in the preferred direction. The time course of the geniculate current is essentially given by the passage of the bar over the ON portion of the single subfield. $b$, We here plot the same, excitatory cortico-cortical current (solid line) compared to the net input current (dotted bold line; see also Fig. 14d), defined as the difference between the cxcitatory current due to the geniculate input and the combined (GABA $\mathrm{A}_{\mathrm{A}}$ plus $\mathrm{GABA}_{\mathrm{B}}$ ) inhibitory currents to the pyramidal neuron. 


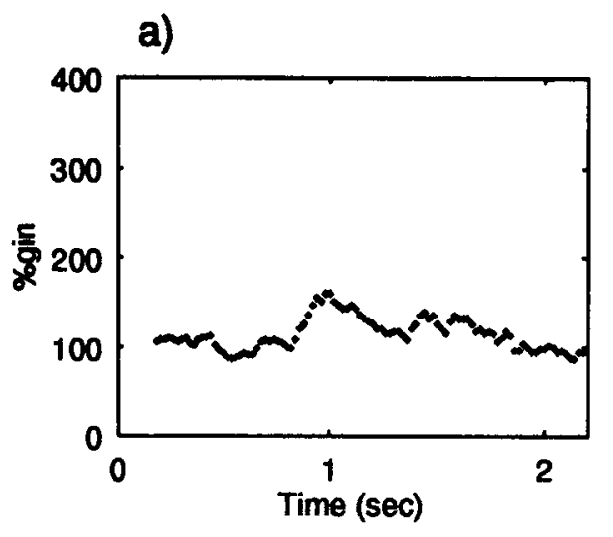

b)

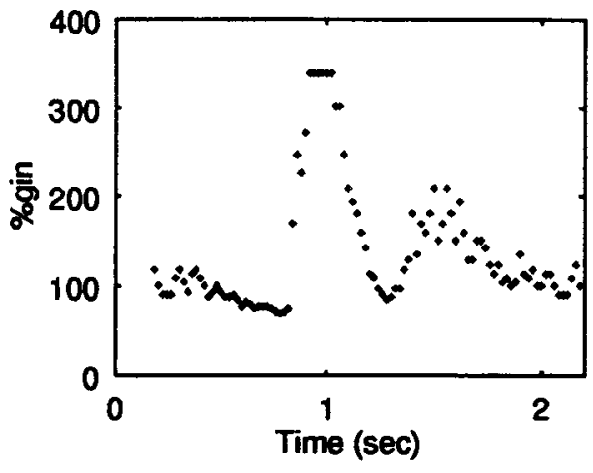

c)

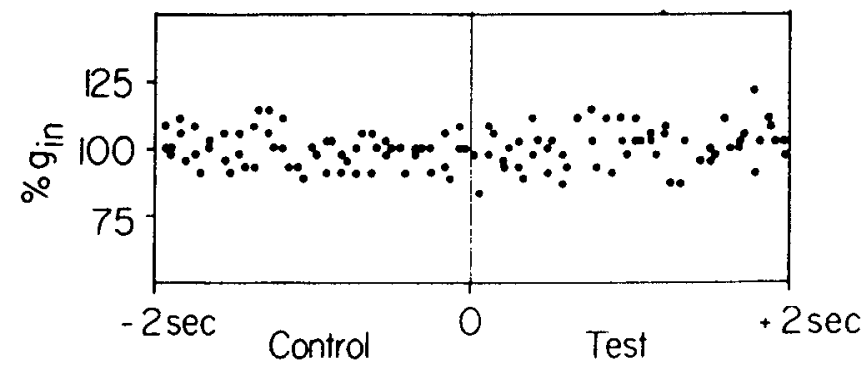

Figure 6. Somatic conductance changes during null direction motion. Shown is the percent change in somatic input conductance as a function of time for a direction-selective pyramidal neuron during stimulation by a bar moving in the null direction. The input conductance is computed as discussed in the text. $a$, Cortical amplifier model: the small excitatory input from the LGN afferents is "vetoed" by a small inhibitory inpui, requiring only a moderate conductance increase. $b$, A much larger conductance increase is required in the feedforward model (with purely nonlagged input) due to the large LGN-mediated excitation. $c$, Estimated conductance change in a layer 6 pyramidal cell in the anesthetized cat in the absence of a visual stimulus (Control) and during null direction stimulation (Test; Douglas et al., 1988); $\% g_{\text {in }}$ is estimated from the decrement in membrane voltage evoked by hyperpolarizing current pulses (20-30 msec, $0.1-0.5 \mathrm{nA}$ ). No significant conductance change occurs (the significance level is $25 \%$ of baseline.)

(Fig. 6a). In contrast, the feedforward network's conductance increased by over three times the baseline (Fig. $6 b$ ).

\section{Contrast dependence of response and directionality}

For the cortical amplifier model, the contrast-response curve of pyramidal neurons in the preferred direction in response to a moving sinusoidal grating (Fig. $7 b$ ) has a threshold close to $0 \%$ contrast and is quite linear on a log-log scale with a slope of
0.62 (decade $\mathrm{Hz} /$ decade $\%$ contrast). Although physiologically there is much variability (Albrecht and Hamilton, 1982), these characteristics are consistent with physiological data (Dean, 1981; Holub and Morton-Gibson, 1981; Tolhurst et al., 1981a; Albrecht and Hamilton, 1982; Ohzawa et al., 1982; Albrecht and Geisler, 1991). The feed-forward case's contrast-response function is quite similar to that of the cortical amplifier, despite small differences in threshold. The LGN contrast-response curve compares well with physiological data (Shapley and Perry, 1986; Saul and Humphrey, 1990). The strength of the cortical amplifier's response decreases dramatically when the excitatory cortico-cortical connections are removed (Fig. $7 \mathrm{~h}$ ), demonstrating the extent to which they amplify the geniculate input.

The model pyramidal neurons respond very little in the null direction, and the direction index is between 80 and $100 \%$ for most contrast values (Fig. $7 e$ ). The invariance of the direction index over a broad range of contrast is characteristic of visual cortical neurons (Fig. 7e; Dean, 1980; Li and Creutzfeldt, 1984; Orban, 1984; Tolhurst and Dean, 1991). Over 20\% of area 17 neurons (and in particular, area 17 simple cells) have direction indices at the optimal velocity between 80 and 100\% (Albus, 1980; Berman et al., 1987; Gizzi et al., 1990; Reid et al., 1991; Tolhurst and Dean, 1991; DeAngelis et al., 1993; McLean and Palmer, 1994).

\section{Velocity dependence of response and directionality}

A strong test of any model of direction-selective cells in area 17 is whether model neurons are velocity low-pass, as are 63\% of area 17 cortical neurons (Fig. 8e; Orban et al., 1981a; Orban, 1984). These neurons respond very well to low velocities and little to velocities above $20 \% \mathrm{sec}$. This property does not originate from LGN neurons, which have tuned, band-pass velocity-response curves with strong responses at high velocities (Fig. 8b; Dreher and Sanderson, 1973; Lee and Willshaw, 1978; Frishman et al., 1983; Orban et al., 1985; Gulyas et al., 1990). A further test is the extent to which direction selectivity persists over a wide range of velocities; indeed, velocity low-pass cells usually have a flat DI-velocity relationship (Orhan et al., 1981 b; Orban, 1984; Fig. 8f).

Model LGN neurons have physiologically plausible velocityresponse curves (Fig. $8 a$ ), and the feedforward model's dependence on velocity (Fig. 8d) is similar, with the addition of a threshold, further reducing the peak response at low velocities.

In contrast, the cortical amplifier's velocity tuning curve (Fig. $8 c$ ) is qualitatively similar to area 17 velocity low-pass neurons. In particular, its response drops off by only $35 \%$ of the maximum response $(70 \mathrm{~Hz})$ at very low velocities. The response at the lowest velocity tested $\left(0.33^{\circ} / \mathrm{sec}\right)$ is much larger than that at the highest velocity $\left(40^{\circ} / \mathrm{sec}\right)$. A remaining discrepancy is that for our cells, the cutoff at high velocities is above area 17 neurons, but similar to that of the geniculate input.

Similar to velocity low-pass ncurons, the cortical amplificr model's dependence of direction index (DI) on velocity is relatively flat over two orders of magnitude (Fig. 8c), reflecting the small response in the null direction at all velocities; this invariance depends on two varieties of GABA mediated inhibition, as explained in the following section. The Mean Direction Index (MDI) is $76 \%$, indicating that the cell is direction-selective in Orban's (1984) nomenclature, rather than direction asymmetric. At high velocities, direction selectivity is less strong, which parallels physiological data showing that a majority of cortical neurons having a direction preference that is stable with temporal 
a)

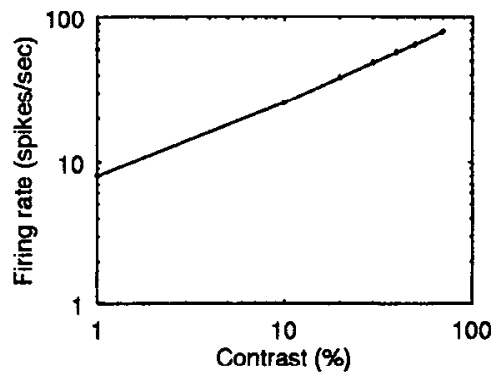

d)

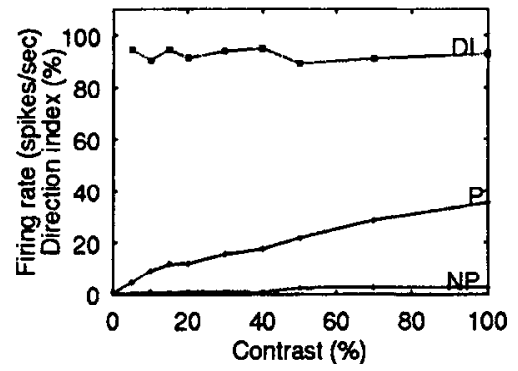

b)

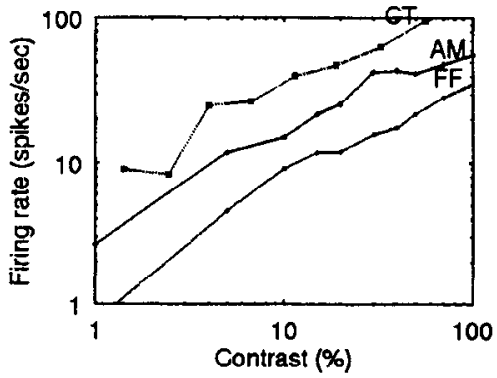

e)

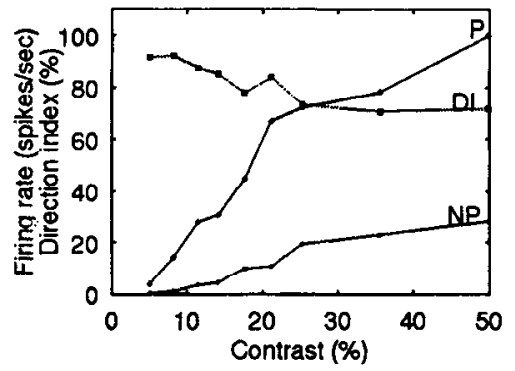

c)

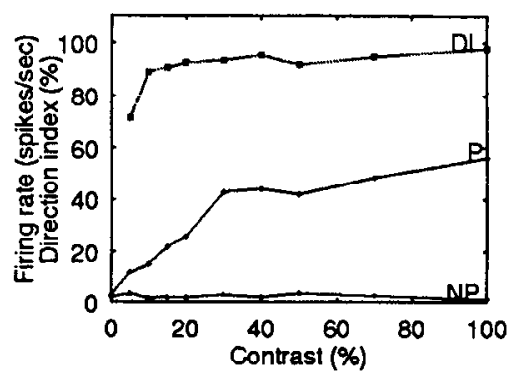

f)

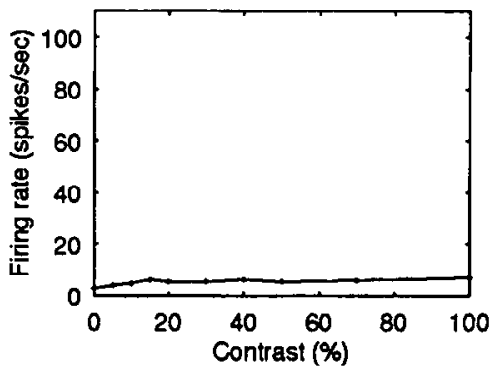

Figure 7. Contrast-response curves. Relationship between the visual contrast (Eq. 2) of a moving sinusoidal grating (1Hz, $1 \mathrm{c} / \mathrm{deg}$ ) and the peak firing rate for different stages in our model, compared to physiological data (see text). $a$, Peak geniculate response given by the Victor (1987) model. $b$, The amplitude of the first Fourier harmonic component from a cortical neuron in cat area 17 (label $C T$; adapted from Albrecht and Hamilton, 1982) compared to the response in the preferred direction for pyramidal neurons in the cortical amplifier $(A M)$ and in the feedforward model $(F F)$. The next three panels show the peak response in the preferred $(P)$ and null direction $(N P)$ of motion as well as the direction index $[D I=(P-N P) / P$; Eq. 5] for pyramidal neurons in the cortical amplifier $(c)$ or in the feedforward model $(d)$ as well as for a simple cell in cat area 17 ( $e$; responding to a $2 \mathrm{~Hz}$ drifting sinusoidal grating; adapted from Tolhurst and Dean, 1991). Both models are direction selective over the full range of contrasts. $f$, Peak response to motion in the preferred direction in the cortical amplifier model in the absence of any excitatory, corticocortical connections.

a)

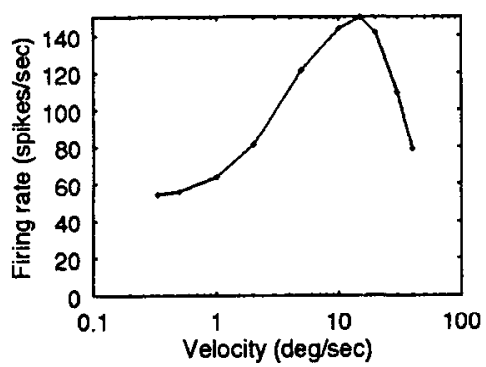

d)

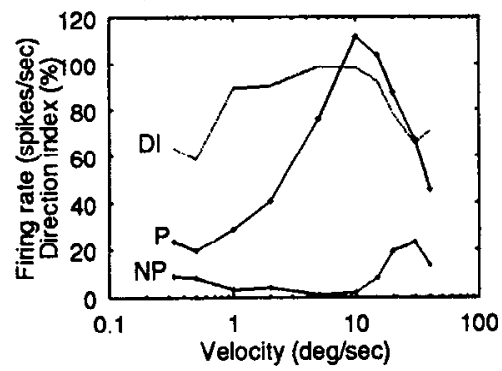

b)

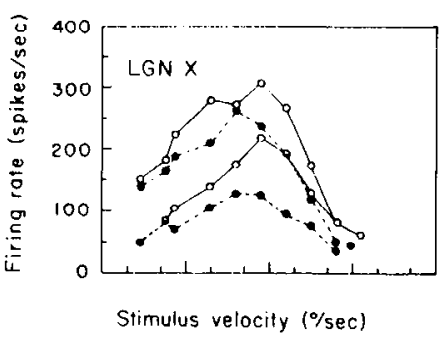

e)

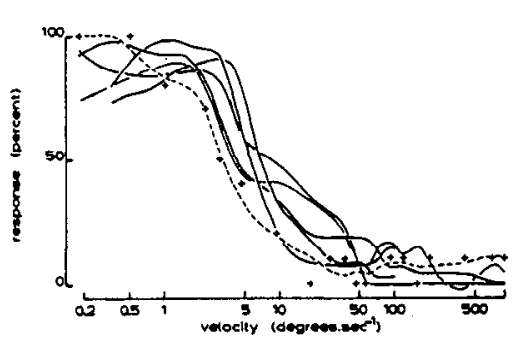

c)

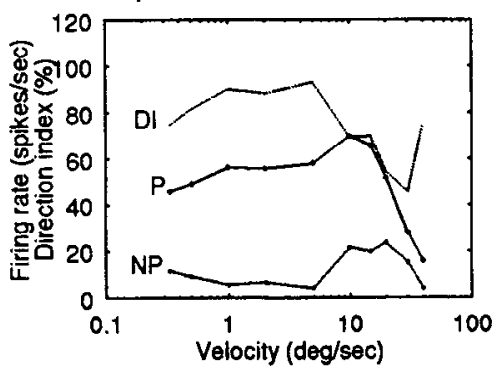

f)

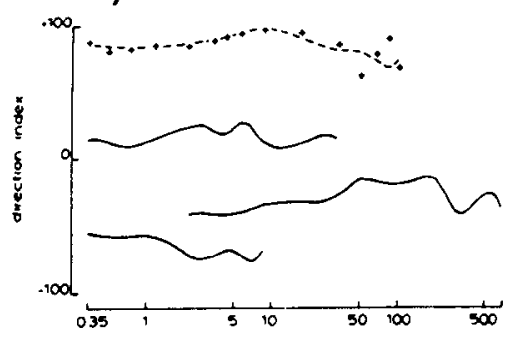

Figure 8. Velocity-response curves. Shown is the peak firing rate for a $70 \%$ contrast bar as a function of its velocity at different stages in our model, compared to physiological data. $a$, LGN model peak response given by the Victor (1987) model. $b$, Peak response of X geniculate cells in the adult, anesthetized cat (Frishman et al., 1983). The following two panels show the peak response in the preferred $(P)$ and null direction $(N P)$ of motion as well as the direction index $[D I=(P-N P) / P ; \mathrm{Fq} .5]$ for pyramidal neurons in the cortical amplifier $(c)$ or in the feedforward model (d). Both feedforward and cortical amplifier models are direction selective over two orders of magnitude of speed. $e$, Representative examples of velocity-response curves from velocity in low-pass cells in cat visual cortex (Orban, 1984, Fig. 8/5C). $f$, Examples of flat velocity-direction index (velocity-DI) curves from recordings in the adult cat (Orban, 1984, Fig. 8/11A) Note that by convention the DI is negative if the preferred direction has a downward component. 
a)

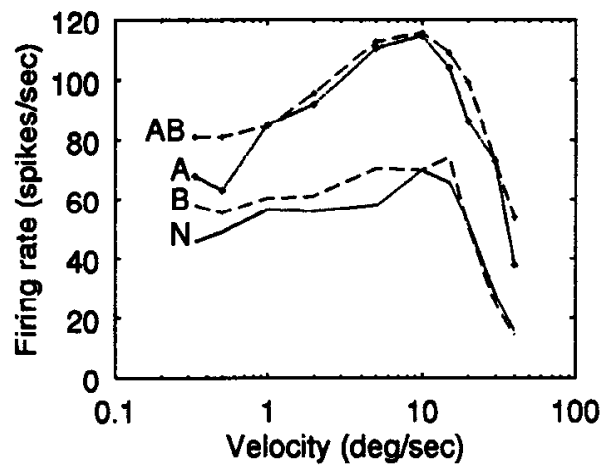

c)

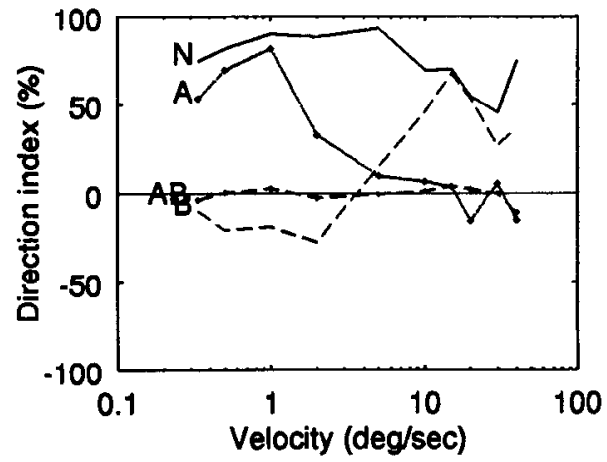

b)

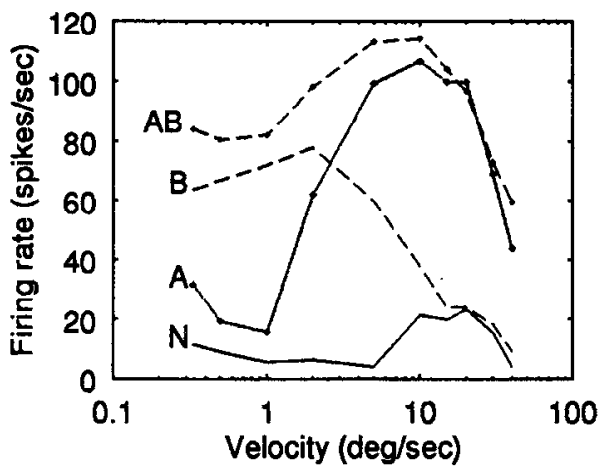

d)

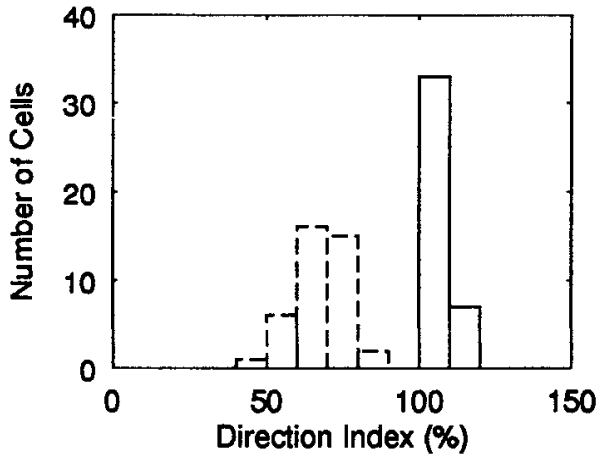

Figure 9. Blocking inhibition and direction selectivity. The first two panels show the peak firing rate for a $70 \%$ contrast bar as a function of velocity for motion in the preferred $(a)$ and in the null direction $(b)$. The $N$ curve indicates the normal response for the cortical amplifier. The peak firing rate increases when fast "shunting" $\mathrm{GABA}_{\mathrm{A}}$ inhibition is blocked (curve A). Removing only slow hyperpolarizing GA$\mathrm{BA}_{\mathrm{B}}$ inhibition leads to curve $B$, while curve $A B$ is obtained in the absence of any inhibition. The associated progressive loss in direction selectivity is document for the pyramidal cells in $c$. Blocking fast $\mathrm{GABA}_{\mathrm{A}}$ inhibition leads primarily to a loss of $\mathrm{DI}$ at high speeds, while the blockade of $\mathrm{GABA}_{B}$ inhibition primarily affects DI at low speeds. In these simulated experiments, inhibition to all cells was eliminated. In $d$ we demonstrate the effect of blocking both $\mathrm{GABA}_{\mathrm{A}}$ and $\mathrm{GABA}_{\mathrm{B}}$ inhibition to a single pyramidal cell. Such an experiment was carried out by Nelson et al. (1994) using GABA blockers intracellularly. DI was assessed with a $70 \%$ contrast bar. The average DI for all 40 pyramidal cells in the normal case (solid boxes) is $108 \% \pm 2 \%$. When blocking inhibition to a single pyramidal cell only, DI in that cell is reduced to $68 \%$ $\pm 8 \%$ (dashed boxes; here carried out for each pyramidal cell in the network). frequency lose part or all of their direction selectivity above 1 or $2 \mathrm{~Hz}$ (corresponding to 4 or $10 \% \mathrm{sec}$; Saul and Humphrey, 1992).

\section{GABA blocking experiments}

In the model, $\mathrm{GABA}_{\mathrm{A}}$ receptors give rise to short-latency, transient inhibition; in contrast, GABA $_{B}$ is associated with longlatency, prolonged inhibition (see Table 1). Paralleling these difference in dynamics, $\mathrm{GABA}_{\mathrm{A}}$ and $\mathrm{GABA}_{\mathrm{B}}$ are responsible for model direction selectivity at different velocities. At low velocities, there is a large time difference in the onset of the LGN input to smooth and pyramidal neurons, and $\mathrm{GABA}_{\mathrm{B}}$ mediates the inhibition that vetoes the response in the null direction. At high velocities, the difference in time of onset is small, requiring short-latency $\mathrm{GABA}_{\mathrm{A}}$ inhibition for direction selectivity. Therefore, the model can be used to make specific predictions about the effect of blocking $\mathrm{GABA}_{\mathrm{A}}$ or $\mathrm{GABA}_{\mathrm{B}}$ or both. Figure 9 illustrates how the cortical amplifier's velocity-response and DI curves transform under partial or complete block of inhibition, as in physiological experiments involving iontophoresis of antagonists (see, for instance, Sillito, 1977).

In the null direction, blocking $\mathrm{GABA}_{\mathrm{A}}$ receptors increases the response dramatically at high velocities, thereby abolishing direction selectivity (Fig. 9c). It has little effect at low velocities. Conversely, blocking $\mathrm{GABA}_{\mathrm{B}}$ receptors strongly increases the null response at low velocities-eliminating direction selectivity here-but very little at high velocities. As expected, blocking both varieties of inhibition abolishes direction selectivity at all velocities. These results can be contrasted with the outcome of physiological experiments, where direction selectivity diminishes strongly or disappears under GABA Alockade (Sillito, 1975,
1977; Wolf et al., 1986) but does not appear to be reduced by $\mathrm{GABA}_{\mathrm{B}}$ blockade (Baumfalk and Albus, 1988).

In the preferred direction, blocking $\mathrm{GABA}_{\mathrm{A}}$ results in a velocity- response curve that is velocity broadband (for the definition of velocity broadband see Orban, 1984) and quite similar to the LGN model's curve (Fig. 8a), except at low velocities. In particular, the response at velocities higher than $20 \% \mathrm{sec}$ is large, as in LGN neurons and unlike area 17 velocity low-pass neurons. $\mathrm{GABA}_{\mathrm{A}}$ feedforward inhibition is responsible for the upper velocity cutoff.

$A$ variant of that experiment is to block both $\mathrm{GABA}_{\mathrm{A}}$ and $\mathrm{GABA}_{B}$ receptors onto a single pyramidal cell and to measure direction selectivity in that particular neuron before and after the block. Such an experiment can be repeated for each neuron in the cortical amplifier in turn, and the results plotted as histograms of the distribution of direction selectivity indices before and after blockade (Fig. 9d). The response measure used in this case was the average number of spikes while the stimulus is in the neuron's receptive field; the neurons' firing rate was depressed below the spontaneous level in the null direction, resulting in direction selectivity indices larger than $100 \%$ for all neurons. Blocking inhibition in a single neuron gives strikingly different results from blocking inhibition in all neurons. Direction selectivity diminishes but is by no means abolished; similar results were obtained experimentally (Nelson et al., 1994).

The cortical amplifier model maintains direction selectivity down to velocities as low as $0.33 \% \mathrm{sec}$ (see Fig. 8), in agreement with physiological data (Orban, 1984; Duysens et al., 1987; Saul and Humphrey, 1992a). There is a direct numerical relationship between this low velocity limit and the duration of $\mathrm{GABA}_{B}$ inhibition. For motion at low velocities in the null direction, there 


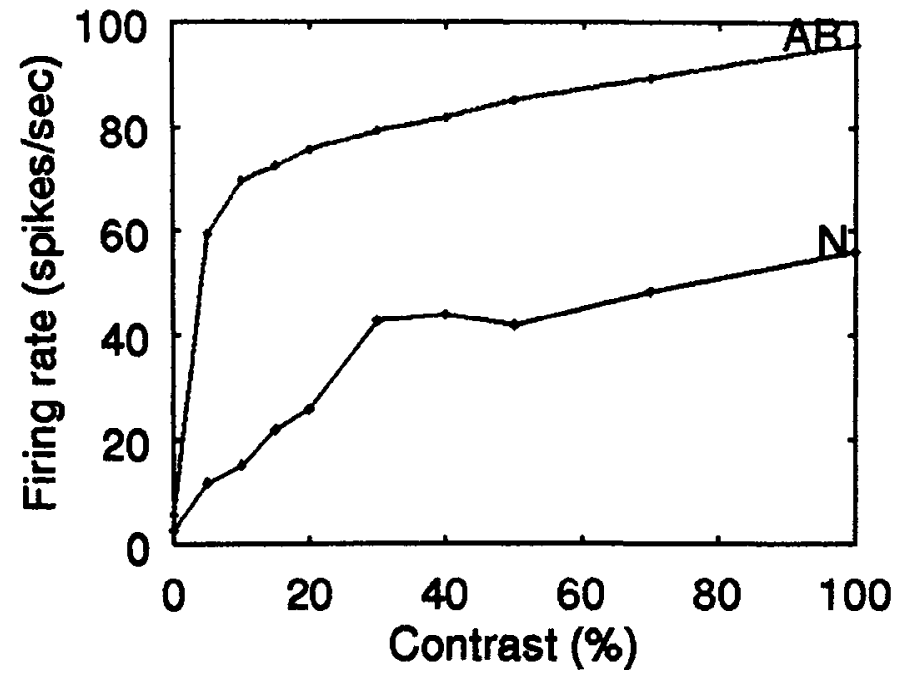

Figure 10. Blocking inhibition and contrast-response curve. This figure shows the peak firing rate for a moving sine grating $(1 \mathrm{~Hz}, 1 \mathrm{c} / \mathrm{deg})$ as a function of contrast for motion in the preferred direction, for the cortical amplifier model $(N)$ and while blocking both $\mathrm{GABA}_{\mathrm{A}}$ and GA$\mathrm{BA}_{\mathrm{B}}(A B)$. Blockade dramatically increases the initial gain of the contrast-response curve, as well as the firing rates at high contrast, but does not cause saturation of the response.

is a time interval when the bar has left the smooth neurons' receptive field but is still stimulating the pyramidal neurons; since the spatial displacement is $5^{\prime}$, this interval lasts $250 \mathrm{msec}$ at $0.33 \% \mathrm{sec}$, approximately equal to the duration of $\mathrm{GABA}_{B}$ synaptic conductance changes in the model; larger spatial displacements or lower velocities would imply a loss of direction selectivity. In the model, the ratio of the spatial displacement and $\mathrm{GABA}_{\mathrm{B}}$ 's timc constant will determine the lowest velocity for which direction selectivity is still observed.

In addition to its role in direction selectivity, inhibition has a strong influence on the contrast-response curve, too. Figure 10 compares the response to contrast when blocking both $\mathrm{GABA}_{\mathrm{A}}$ and $\mathrm{GABA}_{\mathrm{B}}$ to the regular case (as in Fig. 7b). The initial gain of the contrast-response curve is very much increased by blockade. Although saturation still occurs under blockade, the model neurons discharge at far higher rates for saturating contrasts.

\section{Linearity to superposition}

Ferster and his colleagues (Jagadeesh et al., 1993) carried out an elegant set of intracellular experiments in direction-selective simple cells. After removing action potentials from individual voltage traces with a median filter, they showed that the (somatic) membrane potential signal evoked by a drifting sinusoidal grating can be predicted from the linear sum of responses to stationary contrast reversal gratings at several spatial phases, seemingly implying a simple linear feedforward model of direction-selective simple cells.

The Jagadeesh et al. (1993) linearity test is based on expressing drifting sinusoidal gratings as sums of eight stationary contrast-reversal gratings at specific spatial and temporal phases. With $\omega$ the temporal frequency of the grating and $k$ its spatial frequency, simple trigonometry implies

$$
\begin{aligned}
& \sin (k x \pm \omega t) \\
& \quad=\frac{1}{4} \sum_{n=0}^{7} \sin \left(k x+n \frac{\pi}{8}\right) \cdot \sin \left(\omega t+\frac{\pi}{2} \mp n \frac{\pi}{8}\right)
\end{aligned}
$$

Let $R(x)$ denote the neuron's somatic membrane potential in response to a stimulus $x$. If the cell's response is linear (according to Eq. 7) the response to a drifting grating can be predicted from responses to stationary gratings. The predicted response can be calculated from the equation

$$
\frac{1}{4} \sum_{n=0}^{7} R\left[\sin \left(k x+n \frac{\pi}{8}\right) \cdot \sin \left(\omega t+\frac{\pi}{2} \mp n \frac{\pi}{8}\right)\right] \text {. }
$$

The validity of this superposition property for the feedforward and cortical amplifier models was assessed by comparing the response predicted from stationary gratings to the actual response to drifting gratings.

In our simulations, the average somatic potential (computed after removing action potentials via the same median filter as the one used by Jagadeesh et al., 1993) in the preferred and null directions could be predicted with an accuracy comparable to the cxpcrimental results (Fig. 11). There was no necd to adjust any parameters specifically to obtain the fit. For the cortical amplifier, this result is surprising in view of the importance of amplification for the model's functioning.

The preferred direction of motion as well as the direction index measured from the modulations of the intracellular somatic membrane potential (see Materials and Methods) could be predicted from the responses to the stationary gratings. The actual indices were $43.5 \%$ and $33.3 \%$ for the cortical amplifier and feedforward models, respectively, while the predicted indices were $66.0 \%$ and $39.4 \%$. The direction index measured intracellularly (using the peak-to-peak amplitude of the modulation) was much smaller than the direction index measured from the peak firing rate in both cortical amplifier $(43.5 \%$ vs $93.2 \%$ ) and feedforward models ( $33.3 \%$ vs $97.4 \%$ ), as has been observed in cat visual cortex (Jagadeesh et al., 1993).

Since there are many nonlincaritics in the cortical amplificr, an explanation of why that model passes the superposition test requires detailed analysis (Suarez, 1995b). We will give here only a brief overview of the argument. The first main nonlinear operation present in both feedforward and cortical amplifier models is half-wave rectification in the LGN neurons. It results in a LGN current to the pyramidal neurons that is half-wave rectified instead of being a full sinusoid as in a linear system. Inhibitory currents to the pyramidal neurons are also half-wave rectified. The end result is that the waveform of the total current to pyramidal neurons has many higher-order Fourier components, for the responses to both moving sine wave gratings and stationary, contrast-reversal sine wave gratings. These nonlinear components in the responses could prevent linear superposition. However, many such waveforms, shifted in time, are summed before obtaining the current that is responsible for the potential shown in Figure 11. For the sum of stationary contrast reversal gratings, the responses to several gratings with different spatial and temporal phases are summed. In that sum, Fourier components in the waveforms that are higher than first order will mostly cancel out. For the moving gratings, on the other hand, there is no explicit summation; however, the inputs to the pyramidal and smooth neurons originate from geniculate neurons at five spatial positions. The waveform of the total LGN current to both pyramidal and smooth neurons is effectively the sum of five waveforms corresponding cach to current from LGN ncurons at one spatial position. Again, the resulting waveform is highly sinusoidal. Thus, superposition holds. A suitable arrangements of ON and OFF subfields-which we did not implement here- 
a)

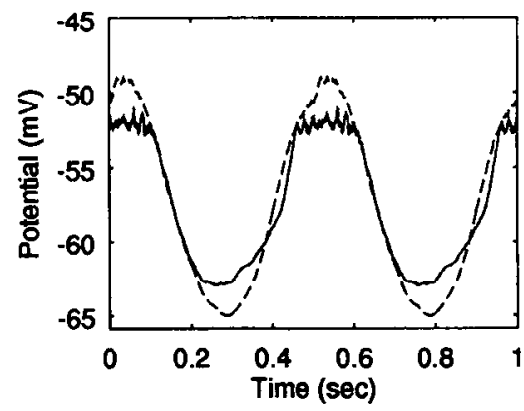

c)

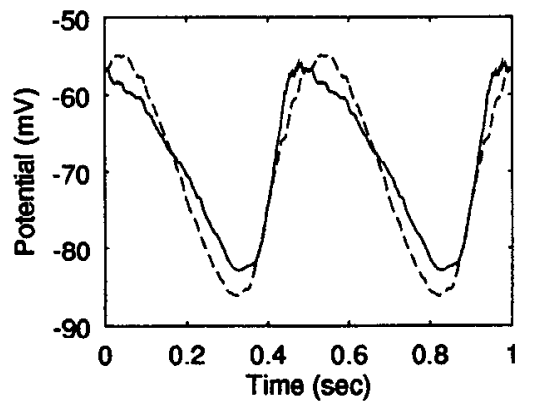

ө)

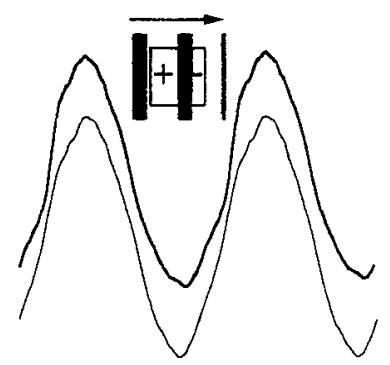

b)

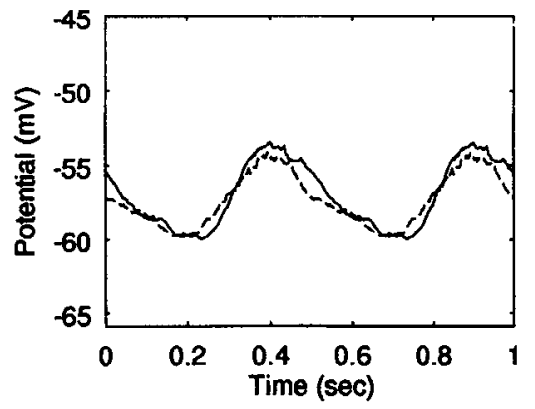

d)

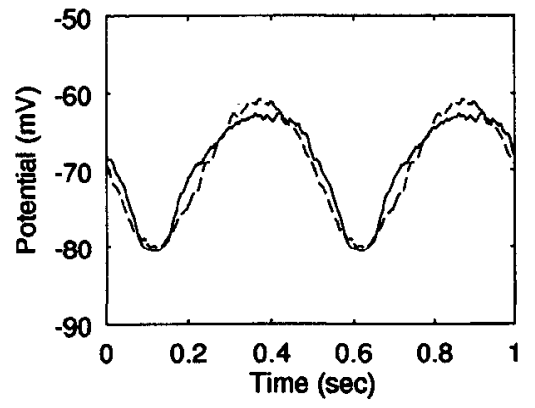

f)

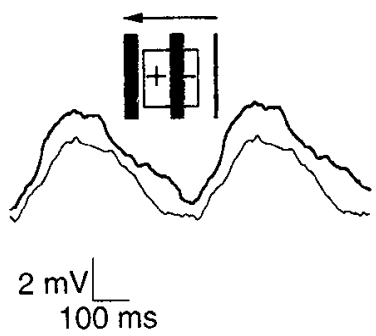

Figure 11. Grating superposition test. The first four panels compare the modulations in membrane potential evoked (continuous) by 1 cycle/deg sine wave grating, drifting in two directions at 2 $\mathrm{Hz}(2 \% \mathrm{sec})$, and the response predicted (dashed) from summing stationary contrast reversal gratings, for one cell in both cortical amplifier and feedfor ward models. Each trace is an average of the response to 57 grating cycles. The last two panels compare evoked (thick lines) and predicted (thin lines) responses for a simple cell in cat visual cortex (Jagadeesh et al,, 1993). Preferred $(a)$ and null direction $(b)$ for the cortical amplifier model (100\% contrast gratings); preferred (c) and null direction $(d)$ for the feedforward model (50\% contrast gratings); and preferred $(e)$ and null direction $(f)$ for the simple cell in cat visual cortex. Surprisingly, superposition holds for both feedfor ward and cortical amplifier networks, as in cat simple cells. could possibly also contribute towards linearity in a feedforward network.

The second main nonlinear operation is unique to the cortical amplifier and originates from excitatory cortico-cortical connections. These connections amplify the sinusoidal geniculate input current to the pyramidal neurons only in its positive phase, when the pyramidal neurons are discharging. This nonlinear amplification should result in an asymmetric sinusoid with a much larger positive phase, and should therefore disrupt the superposition test. However, in its positive phase, the LGN current by itself already brings the pyramidal neurons to threshold (otherwise there would be no action potentials and no amplification through excitatory cortico-cortical connections). Since the pyramidal neurons are already at threshold, this excitatory cortico-cortical current goes into producing additional spikes at the cell body (that acts like a current sink; Bernander et al., 1994), rather than further depolarizing the cell body. These spikes are then stripped out by the median filter. Thus, the feedback current does not influence much the average transmembrane potential, ensuring that the superposition test holds (in real cells, the voltage threshold rises during a quick burst of spikes, explaining why the membranc potential after the spike stripping has a round appearance at the top of the voltage excursion; see Fig. $11 f$; in our simple model cells, the voltage threshold remains constant, accounting for the flat "tops" in Fig. 1la). This mechanism can be tested experimentally through blockade of the spiking mechanism in one cell using pharmacological agents.

In summary, nonlinearities in both feedforward and cortical amplifier models originating from half-wave rectification of LGN inputs cancel because of spatial summation in the cortical neurons and spatio-temporal summation through the superposition test. Nonlinearities originating from amplification in the positive phase of the input current to the pyramids are mitigated by current sinking during spike production.

\section{Analysis of a simplified cortical amplifier model}

The detailed biophysical model is not analytically tractable, because it is based on a high dimensional system of coupled, nonlinear partial differential equations. Nevertheless, it is possible to gain some qualitative insight into the cortical amplifier model's behavior through analysis of reduced models.

When a constant current is injected into the soma of a single pyramidal cell, the neuron responds with a stream of action potentials. The relationship between the current's amplitude $I$ and the resulting spiking frequency is known as the current-discharge curve, $F_{i}(I)$. Initially during stimulation, this curve is stecp. However, duc to the inflow of calcium, causing activation of a calcium-dependent potassium current and adaptation of the firing frequency, the slope is later much reduced. The time constant of this adaptation is $15-50 \mathrm{msec}$ (Ahmed et al., 1995). The 
a)

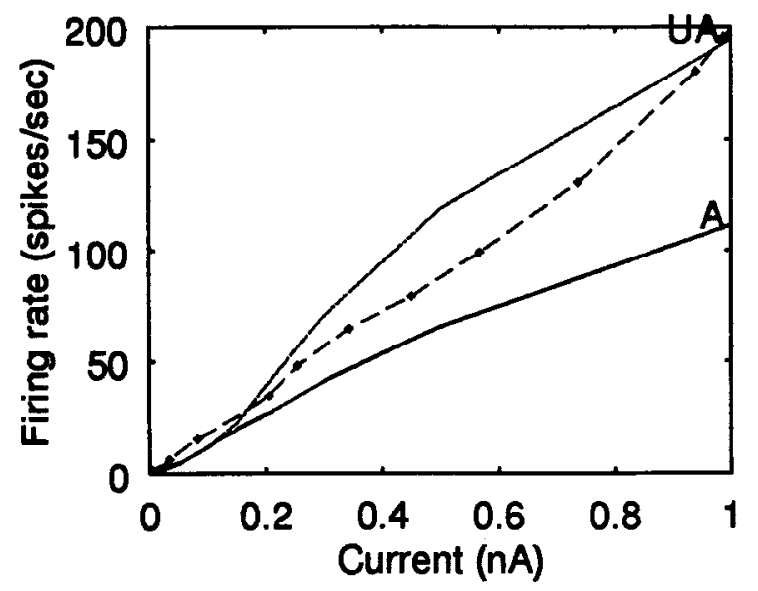

b)

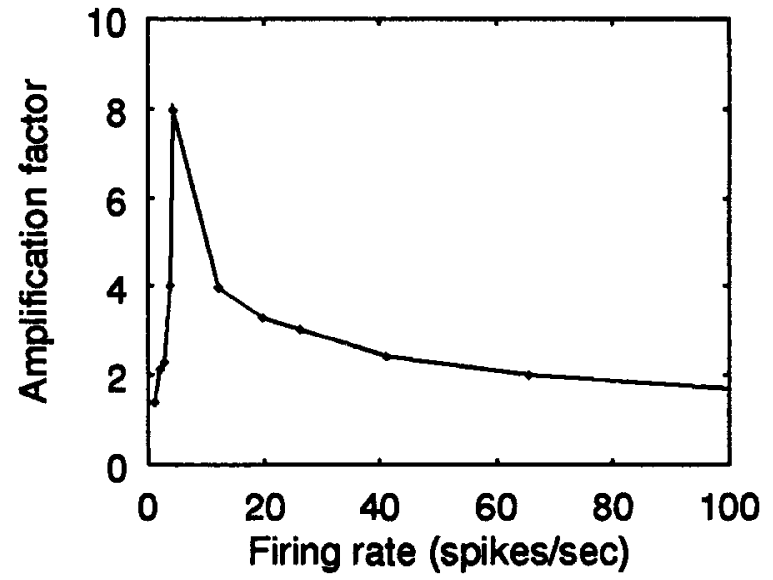

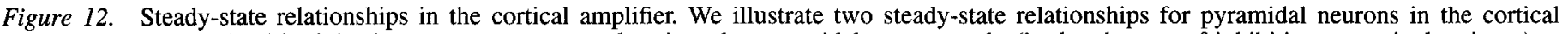

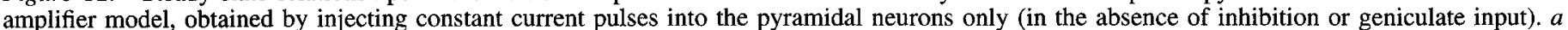

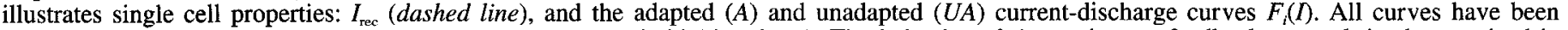

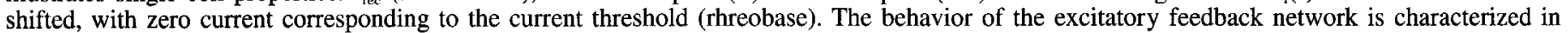

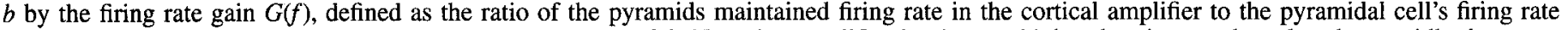

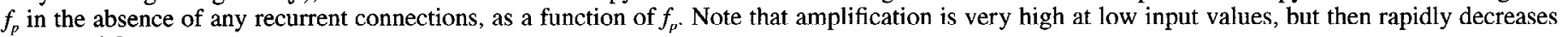
to around 2 .

unadapted and adapted current-discharge relations of a typical model pyramidal cell are shown in Figure $12 a$. The slope of the adapted curve is $112 \mathrm{~Hz} / \mathrm{nA}$ for the first $\mathrm{nA}$ of input current. The $F_{i}$ function is not strictly linear because of refractoriness and other nonlinearities, but for the qualitative purposes of the following discussion, the $F_{i}$ curve can be considered linear. For the moment, let us ignore adaptation, although it is important for fully understanding the dynamics of the network.

At the heart of the Canonical Microcircuit is massive, recurrent excitatory feedback, characterized by $I_{\text {rec }}$, the function relating the input frequency of all excitatory, cortico-cortical synaptic inputs to a pyramidal cell (all assumed to fire at the same constant, frequency) to the maintained current flowing from these synapses into the soma. $I_{\mathrm{rec}}$ is estimated indirectly: a certain constant current is injected into the soma of all pyramidal neurons connected in the cortical amplifier configuration (in the absence of any inhibition), and their maintained firing rate is noted. The total current producing that firing rate is estimated from the adapted current-discharge curve, and the injected current is substracted from the total current to yield the contribution from recurrent excitatory connections. It is sometimes more convenient to display the inverse of $I_{\text {rec }}$ (Fig. 12a).

The discharge frequency of the pyramidal cells at equilibrium is defined implicitly by the requirement that the current-discharge curve, applied to the sum of the input current $I_{\text {in }}$ (delivered to all pyramidal neurons either by the LGN or via an intracellular electrode) and the recurrent current must be equal to the discharge frequency. In other words, the discharge rate $f$ must satisfy (see also Fig. 13):

$$
f=F_{i}\left[I_{\text {in }}+I_{\text {rec }}(f)\right]
$$

\section{A linear Ansatz}

This equation is difficult to solve analytically because of the nonlinearilies present in $F_{i}$ and $I_{\text {rec }}$. Since we seek to isolate the central mechanism underlying the behavior of the cortical amplifier in order to understand its operation, let us assume that both functions are linear:

$$
F_{i}(I)=k_{F_{i}}\left(I-I_{T}\right), \quad I_{T}: \text { threshold }
$$

and

$$
l_{\mathrm{rec}}(f)=k_{\mathrm{rec}} f \text {. }
$$

From Equation 9, the pyramidal neuron discharge rate at equilibrium is now

$$
f=\frac{k_{F_{i}}}{1-\alpha}\left(I_{\mathrm{in}}-I_{T}\right)
$$

where $\alpha=k_{\mathrm{F}_{j}} k_{\mathrm{rec}}$ is the product of the slope of the $F_{i}$ curve and the inverse of the $I_{\mathrm{rec}}$ curve (Fig. 12a). Since the firing frequency must be positive, $\alpha<1$. In addition, linearization implies that the steady-state firing rate is linear in the input current. In our network, this holds only approximately.

An important stcady-statc function is the firing rate gain $G(f)$. It is given by the pyramidal neuron's maintained firing rate for the cortical amplifier divided by the pyramid firing rate in the absence of any excitatory cortico-cortical connections and is expressed as a function of firing rate in the absence of excitatory cortico-cortical connections. $G(f)$ measures the effectiveness of the recurrent connections in driving the pyramidal neurons, relative to the LGN input.

In the linear approximation, the firing frequency in the absence of recurrent connections is given by Equation 10, resulting in a firing rate gain:

$$
G(f)=\frac{1}{1-\alpha} .
$$

As $\alpha$ increases from $0, G$ increases, eventually diverging as $\alpha$ $\rightarrow 1$.

The cortical amplifier's behavior is qualitatively similar, although its gain is not independent of the firing frequency (Fig. $12 b$ ). At low firing rates, the gain $G(f)$ is large, because the slope of the adapted $F_{i}$ and the inverse of the $I_{\text {rec }}$ curve are very nearly identical, implying that $\alpha$ is close to 1 . For larger inputs, the slopes of the two curves diverge (Fig. 12b) and the gain of 
(a)

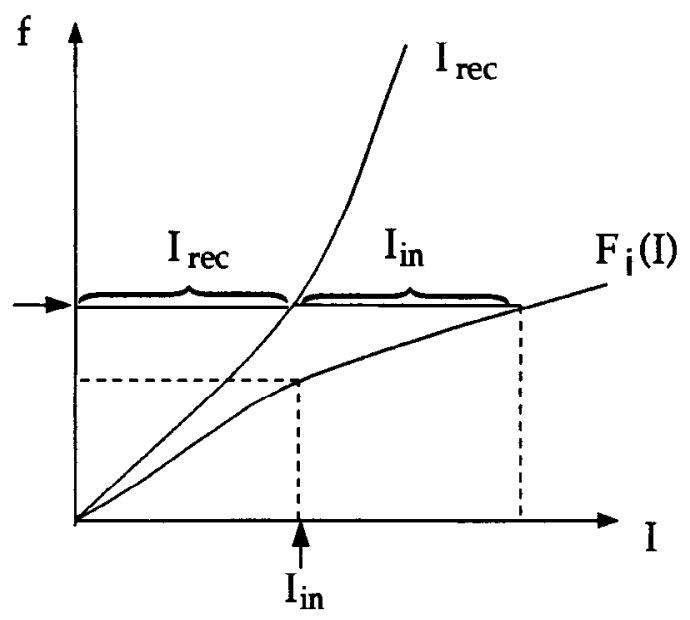

(b)

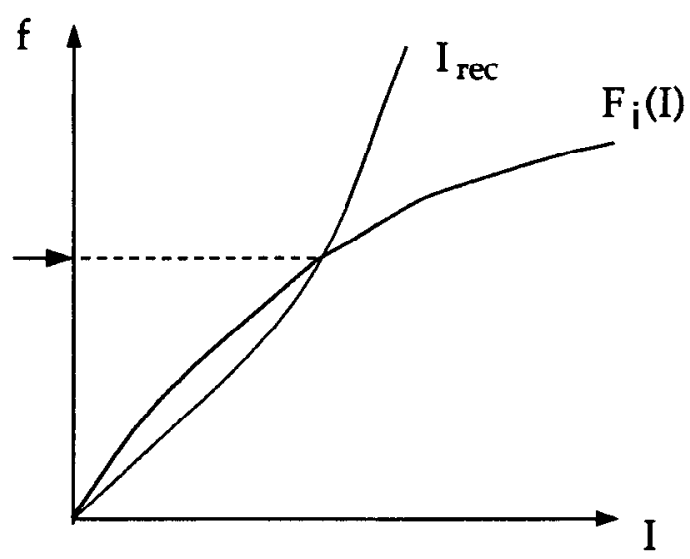

Figure 13. Determining the steady-state discharge frequency. We represent here schematically the relations that determine the steady-state discharge frequency of pyramidal neurons in the cortical amplifier model. $a$, For a given input current $I_{\text {in }}$ (vertical arrow), steady-state occurs at the firing rate (horizontal arrow) for which the horizontal separation between the two curves $I_{\text {rec }}$ and $F_{i}$ is equal to $I_{\text {in }}$. In the absence of excitatory feedback, the firing rate is lower (follow the vertical arrow up to the $f$ axis). As the difference between the slopes of these two curves goes to zero, the gain of the circuit, $G(f)$, as a function of the firing frequency diverges ( $\alpha \rightarrow 1$; see Eq. 13). $b$, If $F_{i}$ is steeper, it may intersect $I_{\mathrm{rec}}$. In that case, there may be sustained discharge in the absence of any input, at the firing rate indicated by the horizontal arrow. In particular, even if the network initially does not fire, any small input will cause it to reach that high sustained firing rate; even if the input is then withdrawn, it will maintain the high discharge frequency (hysteretic mode).

the cortical amplifier decreases as a consequence. The gain $G(f)$ can be increased by adjusting $\alpha$, in particular by increasing the amplitude of the excitatory cortico-cortical synapses (see also Fig. 13).

Despite strong positive feedback in the network, it has no trouble turning off once the LGN input returns to the resting level. The explanation lies in Equation 12. As long as the input current is smaller than the neuron's threshold, the pyramidal neurons do not fire. Note that that equation is only valid if $\alpha=$ $k_{\mathrm{F}_{1}} k_{\text {rec }}$ is less than 1 . This can be understood graphically by looking at Figure 13. The upper panel shows that the steady-state pyramidal neuron firing rate is the firing rate for which the hor- izontal separation between the two curves $I_{\text {rec }}$ and $F_{i}$ is equal to $I_{\text {in }}$ (a graphical interpretation of Eq. 9). If that factor is larger than 1 the network will in general not turn off (Fig. 13b). This hysteretic mode of operation is discussed in detail in Suarez (1995)

\section{Analysis of the velocity-response curve}

The feedback excitatory connections in the cortical amplifier model result in a response that decreases much less at low velocities than the LGN model's (Fig. 8). Furthermore, the response at high velocitics $\left(10^{\circ} / \mathrm{scc}\right.$ and above) is much diminished compared to the LGN neurons. Moving bars are transient stimuli, and these transformations are related to whether the network reaches equilibrium for bar stimulus with a given velocity, which depends in turn on the duration of the stimulus compared to the network's time constant.

Using the linear approximation (Eqs. 10 and 11) and neglecting the membrane time constant, the system can be described by the following differential equation (Suarez, 1995):

$$
\frac{\tau_{\mathrm{syn}}}{1-\alpha} \frac{d f}{d t}=-f+\frac{\hat{w}_{l p}}{1-\alpha} \hat{f}_{l, i}
$$

where $\tau_{\mathrm{syn}}$ is the decay time constant for the excitatory synaptic conductance change $(20 \mathrm{msec}), \hat{w}_{t p}$ the normalized weight of the thalamocortical connection, and $\hat{f}_{l, i}$ the combined LGN and inhibitory input.

The pyramid firing rate $f$ settles to steady-state with a certain time constant, the network's time constant $\tau_{\text {net }}=\tau_{\text {syn }} /(1-\alpha)$. In conditions where there is amplification of the input, that is, when $\alpha$ is slightly smaller than 1 , the network's time constant becomes much larger than $\tau_{\text {syn }}$.

This very long time constant could, in principle, explain the enhanced response of the cortical amplifier at low velocities, as in Maex and Orban (1992). However, Figure $14 a$ shows that for a constant current injection lasting $25 \mathrm{msec}$, the network already reaches the firing rate that it will eventually settle to (after adaptation is complete) if the input were sustained. In other words, for a stimulus duration of $25 \mathrm{msec}$ or more, the network's amplification, measured from its peak firing rate at that velocity, would be the same as for a sustained stimulus. We can therefore assume - for the purposes of the velocity-response curve-that $\tau_{\text {net }} \approx 25 \mathrm{msec}$, close to $\tau_{\text {syn }}$. This short network time constant originates in the calcium-dependent adaptation in the pyramidal neurons. Indeed, the slope of the unadapted $F_{i}$ is substantially larger than that of the adapted $F_{i}$ (see Fig. $12 a$ ), so that initially $\alpha$ is larger than 1 (Eq. 12). This results in faster growth of the firing rate during the initial portion of stimulus presentation, resulting in the short time constant demonstrated in Figure 14a.

This initial time constant is too short to account for the sharp decrease in amplification between low velocities and a velocity of, say, $5 \% \mathrm{sec}$. Figure $14 \mathrm{~b}$ plots the velocity-response curve obtained when the cortical amplifier's excitatory cortico-cortical connections were removed. The overall shape is very similar to the LGN's velocity-response curve after scaling and thresholding. The response at low velocities is very small. However, as can be seen in Figure $12 b$, the firing rate gain $G(f)$ is much larger for small input firing rates than for large ones. Consequently, the LGN input is more strongly amplified at low than at high velocities.

This argument can be made more quantitative. We multiplied the firing rates in the absence of excitatory feedhack as a function of velocity (Fig. 14b) with $G(f)$ (Fig. 12b). This simple 
Figure 14. Explaining the cortical amplifier's velocity-response curve. $a$, For a constant current injection of 0.1 nA into all pyramidal neurons, peak firing rate as a function of the duration of the stimulus. The inset shows the pyramidal firing rate as a function of time for a sustained current injection. For $0.1 \mathrm{nA}$, the steady-state firing rate is 48 $\mathrm{Hz}$; this firing rale is reached already in $25 \mathrm{msec}$, so in that sense the time constant of the system $\tau_{\text {net }}$ is $25 \mathrm{msec}$. Notice that due to adaptation, the maintained firing rate of the system is lower than its peak firing rate. $b$, Velocityresponse curve obtained in the preferred direction when all recurrent synapses have been removed (continuous), compared to the LGN's velocity-response curve (dashed; see also Fig. $8 a$ ). $c$, Comparison of the velocity response curve for the cortical amplifier in the preferred direction (dashed; see also Fig. 8c) with an approximating curve (continuous) obtained by multiplying the firing rates in $b$ (continuous) by the firing rate gain $G(f)$ from Figure $12 b . d$, The time-course of the net input current in a pyramidal neuron, defined as the geniculate current minus the total inhibitory current, for a $70 \%$ contrast bar moving at $2 \% \mathrm{sec}$ in the preferred direction (see also Fig. $5 b$ ). a)

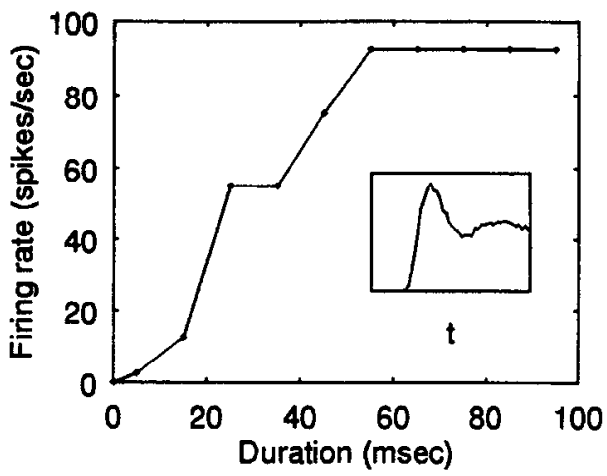

c)

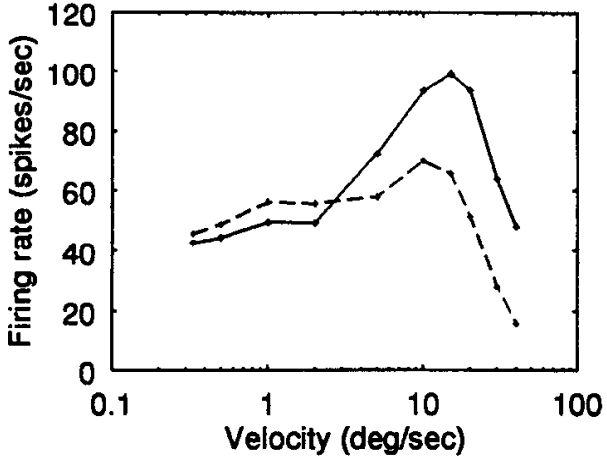

b)

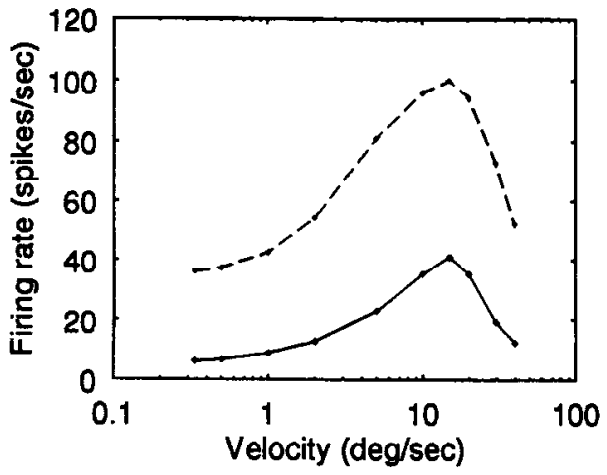

d)

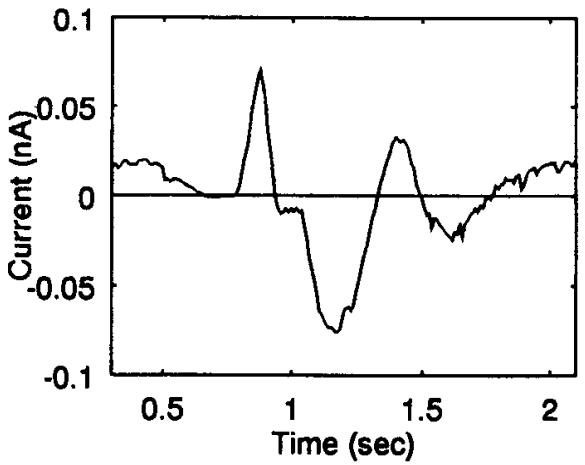

approximation (Fig. $14 c$ ) is remarkably accurate at $5 \% \mathrm{sec}$ and lower velocities, explaining the strong responses to low speeds, despite changes by a factor of two in the geniculate firing rate between $0.33 \% \mathrm{sec}$ and $5 \% \mathrm{sec}$.

At speeds of $10 \% \mathrm{sec}$ and above, the actual amplification is much lower than predicted (Fig. 14c). This reduction arises because the stimulus duration diminishes with velocity, and at some point is too short to allow buildup of excitation in the network.

It is important to realize that stimulus duration is not the same as the dwell time of the stimulus within the center portion of a LGN cell. Because LGN inputs to the pyramidal and smooth neurons overlap spatially, inhibition in the preferred direction arises from the smooth neurons while there is still LGN input to the pyramidal neurons. Therefore, the stimulus duration needs to be estimated from the difference between the excitatory geniculate and total inhibitory currents, called net input current. Figure $14 d$ represents the net input current to a pyramidal neuron for a bar moving at $2 \% \mathrm{sec}$ in the preferred direction. At rest, the LGN background activity is responsible for some positive net input current (about $0.02 \mathrm{nA}$ ). As the stimulus enters the surround of the LGN neurons, their spontaneous response is inhibited, reducing the net input current to zero. When the stimulus enters the center portion of the LGN neurons, the net current quickly increases to about $0.075 \mathrm{nA}$. As the LGN input fields of the smooth neurons overlap with those of the pyramidal neurons, inhibitory current from the smooth neurons quickly reduces the net current to $-0.08 \mathrm{nA}$. Subsequently, the net current first increases due to rebound when the stimulus leaves the pyramids' surround, then goes negative with rebound from the smooth neurons' surround, hefore reverting to its spontaneous background value.
Stimulus duration can be estimated from the largest positive phase of the net input current trace, and is on the order of 50 $100 \mathrm{msec}$. Since the stimulus duration is inversely proportional to velocity, at $10^{\circ} / \mathrm{sec}$ the duration is $10-20 \mathrm{msec}$, which is slightly less than the system's 25 msec time constant. This explains the reduccd amplification at high velocities.

In summary, two processes are responsible for transforming the LGN's velocity-response curve into the cortical amplifier's. First, in contrast with Maex and Orban (1992), the elevated response at low velocities does not originate in the network's time constant being lengthened by the excitatory feedback; instead, it is due to nonlinear amplification that is larger at low than at high LGN inputs. Secondly, the upper cutoff velocity is determined by the duration of the positive phase of the net input current and by the network's time constant, which in this case is only about $25 \mathrm{msec}$, due to calcium-dependent adaptation.

\section{Discussion}

The canonical microcircuit is the embodiment of compelling anatomical observations showing massive excitatory corticocortical feedback connections among spiny stellate and pyramidal cells in mammalian visual cortex (Berman et al., 1992; Peters and Payne, 1993; Ahmed et al., 1994; Peters et al., 1994). Physiological support derives primarily from intracellular recordings in response to electrical pulse stimulation of cortical afferents (Douglas and Martin, 1991) and from pharmacological blockade experiments (Grieve and Sillito, 1991). The role of the present article is to examine how a reduced version of the canonical microcircuit, encompassing the crucial, excitatory, cortico-cortical feedback, operates within the context of a realistic simulation of the dynamics of a small set of cortical neurons. 


\section{Assumptions and limitations}

These simulations involve numerical solutions to a large number (about 1000) of coupled partial differential equations, with a sizable fraction thereof nonlinear, including about 140 cellular and network parameters. This forced us to adopt a number of simplifying assumptions, as discussed in detail at the beginning of Materials and Methods.

Both morphology and physiology of our model neurons were derived from experimentally recorded neurons. Nevertheless, these neurons were extensively simplified and are quite impoverished compared to real neurons, in order to remain within the practical limitations of large scale digital simulations (Wilson and Bower, 1989; Bush and Sejnowski, 1993). In particular, model cells only had three or four compartments and we omitted for now any voltage-dependent synaptic transmission in our network.

Because of these practical limitations, we could not evaluate in general the sensitivity of the model to changes in individual parameters. Thus, our simulations should be taken as evidence a plausible network of spiking neurons can reproduce many aspects of the known phenomenology of simple cells in the adult cat striate cortex. Despite these limitations, it suggests a number of interesting experiments and allows us to understand how such nctworks could opcratc.

This is the principal reason why we discussed the "linearized" model, since it allows us to identify $\alpha$, the product of the slope of the $F_{i}$ and the $I_{\text {rec }}$ curve, as the critical parameter governing the amplification properties of the network. Stability of the linear model requires $\alpha<1$ (see Eq. 13). This implies that the synaptic weight controlling the strength of the cortico-cortical feedback strongly affects the slope of the contrast-response curve.

We modeled a patch of cortex as if it were a small group of direction-selective neurons that are fully interconnected with each other and that are not connected to any neurons outside the group. From what we know about the weak columnar organization of direction selectivity (Payne et al., 1980; Tolhurst et al., 1981b; Berman et al., 1987) and the high divergence and convergence of cortical networks, including long-range connections (Gilbert and Wiesel, 1983; Martin, 1984; Martin and Somogyi, 1985; Gabbott et al., 1987; White, 1989; Braitenberg and Schüz, 1991; Ahmed et al., 1994), these assumptions are unlikely to be true. However, they represent a valid starting point for grasping the cortical network's function. Also, neurons with similar response properties are likely to be more strongly connected, due to Hebbian mechanisms operating in cortex (Miller, 1992; Bliss and Collingridge, 1993).

Our network operates in a domain called mean-field by physicists. In particular, the spikes are temporally dispersed and the network does not rely on the exact temporal alignment of spikes (unlike many of the networks studying temporal synchrony). Spike firing is correlated (see the raster plots in Fig. $4 a$ ) but not at a fine, $1-10 \mathrm{msec}$ level. This allows us to use relatively slow excitatory, cortico-cortical synapses (see Table 1) and a small number of neurons. Faster cortico-cortical synapses would require the use of many more neurons in order to obtain realistic postsynaptic currents with the observed variability. While this is not an issue for cortex, it is an issue for our numerical simulations. We can make the cortico-cortical input considerably slower without changing any of our conclusions.

In order to facilitate our numerical simulations, the smooth neurons received only feedforward input, thereby rendering them insensitive to the direction of motion. Identified smooth (basket) cells in visual cortex are known to share direction selectivity and other receptive ficld propertics with their excitatory neighbors (Martin et al., 1983). Simulations with a much simplified single neuron model (having continuous firing rate output instead of discrete action potentials) that could be simulated substantially faster, showed that suitable response characteristics can be obtained in the presence of these connections, including physiological contrast-response, velocity-response, DI-contrast, and DI-velocity curves. Furthermore, the smouth neurons now showed direction preference.

We also left out a number of other phenomena that could contribute towards direction selectivity; in particular the effect of lagged and nonlagged geniculate input on direction selectivity (Mastronarde, 1987; Saul and Humphrey, 1990, 1992b; Emerson et al., 1992) as well as OFF as well as ON inputs. We plan to investigate these in our future work.

\section{Basic mode of operation}

The results described above support the idea that massive, cortical feedback is a crucial part of normal cortical operations. As argued previously (Douglas et al., 1988), the classical Barlow and Levick, feedforward model of direction selectivity requires large conductance changes in the null direction, greater than $100 \%$ (Fig. $6 b$ ). However, direct measurements of somatic input conductance in the null direction have only demonstrated surprisingly small conductance changes (Fig. $6 c$; Douglas et al., 1988, 1991; Pei et al., 1991; Ferster and Jagadeesh, 1992). In our detailed simulations, we find that the canonical microcircuit shows relatively small changes in conductance (Fig. $6 a$ ), confirming a previous report with much more simplified neurons (Douglas and Martin, 1991).

The recurrent feedback acts as a current amplifier (Fig. 5), enabling a comparatively weak geniculate input to be greatly amplified. In this view, DS arises through inhibition in the null direction combined with amplification of the signal in the preferred direction. Recurrent excitation together with feedforward inhibition realizes a selective cortical amplifier, which amplifies the direction-selective signal only. The result is strong DS at all contrasts and velocities for which there is a response.

This strong amplification does not prevent the cortical neurons from ceasing to respond once the visual input moves out of their receptive fields. Although slightly higher intracortical excitation would allow the network to function in a "hysteretic" mode of operation (Suarez, 1995; Fig. 13b), even then inhibition would prevent the network from firing in the absence of stimulus. In the present simulations, the role of inhibition is to bound the overall level of excitation, to control the gain of the contrastresponse curve and to impose direction selectivity.

The gain of the amplifier is controlled by $\alpha$; the closer $\alpha$ is to one, the larger the gain (Eq. 13). Graphically, in terms of Figure $12 a$, the closer the slope of the $F_{i}$ and the inverse of the recurrent current, $I_{\text {rec }}$, the larger the gain (see also Fig. 13). This could be exploited by a simple adaptation circuit, in which the network continuously adjust the shape of $I_{\text {rec }}$, until a particular gain is achieved.

The cortical amplifier's unique characteristics are strikingly highlighted by the persistence of DS in a neuron despite blocking both the neuron's $\mathrm{GABA}_{\mathrm{A}}$ and $\mathrm{GABA}_{\mathrm{B}}$ receptors (Fig. 9d). This is explained by noting that other cortical cells that retain their direction selectivity provide recurrent, excitatory connec- 
tions to the fiducial neuron. Firm experimental support for this result (Nelson et al., 1994) provides an argument in favor of the canonical microcircuit.

The model's DS is relatively invariant with contrast (Fig. 7), as observed experimentally (Dean, 1980; Li and Creutzfeldt, 1984; Orban, 1984; Tolhurst and Dean, 1991). In the model, this invariance is dependent on a high enough setting of the smoothto-pyramidal $\mathrm{GABA}_{\mathrm{A}}$ and $\mathrm{GABA}_{\mathrm{B}}$ weights; but especially, it requires smooth neurons' thresholds that are low, to ensure inhibition in the null direction even at low contrasts.

\section{Linearity}

The cortical amplifier model includes many nonlinear elements; nevertheless it-like the feedforward model-behaves remarkably linearly to grating superposition (Fig. 11). We conclude that the fact that simple cells in area 17 in the anesthetized cat obey this superposition test (Jagadeesh et al., 1993) does not allow us to distinguish between feedforward and feedback network configurations. This result challenges conventional interpretations that linearity to superposition reflects the fundamental linearity of neurons.

Aspects of this test favor linearity. In particular, the summation of the responses to eight stationary gratings leads to cancellation of these higher components, revealing a dominant linear, sinusoidal component. If, however, the responses to only two stationary gratings are summed, superposition is not nearly as good (Suarez, unpublished observations).

The significance of these findings is also that linear summation contributes in our model to direction selectivity to sine gratings, in agreement with physiological data (Reid et al., 1987, 1991; Albrecht and Geisler, 1991; DeAngelis et al., 1993; McLean and Palmer, 1994).

\section{Velocity dependence}

Most area 17 cortical neurons are low-pass in velocity and temporal frequency. This behavior must be generated in cortex, since geniculate neurons show very different response properties (Dreher and Sanderson, 1973; Ikeda and Wright, 1975; Lee and Willshaw, 1978; Movshon et al., 1978; Derrington and Fuchs, 1979; Orban et al., 1981a, 1985, 1986; Frishman et al., 1983; Gulyas et al., 1990; Maex and Orban, 1992; Saul and Humphrey, 1992a). Moreover the membrane time constant of cortical neurons is too short to provide this low-pass filtering in a feedforward model (Wörgötter and Holt, 1991).

We confirm the validity of this argument, since the feedforward model's velocity-response is far from being low-pass (Fig. 8). In addition, we propose a specific mechanism for the strong response at low velocities, based on our simulations of the canonical microcircuit. As shown in Results, the recurrent feedback connections have a far larger gain $G(f)$ at low than at high inputs (Fig. 12b). This nonlinear amplification is responsible for the strength of the model's response at low velocities, rather than a very long network time constant as in Maex and Orban (1992). The response at very low velocities depends much more on feedback strength than the response at higher velocities. A prediction is that in experiments that reduce the amount of excitatory cortical feedback to a neuron, such as that done by Grieve and Sillito (1991), should affect neuronal responses preferentially at low velocities, and the velocity-response curve might no longer be low-pass in character.

GABA $_{A}$ feedforward inhibition is responsible for the velocity upper cutoff (Fig. 9) by shortening the stimulus duration at ve- locities above $20 \% \mathrm{sec}$, leading to a weak response despite the strong LGN input. That inhibition is responsible for the absence of response at high velocities has been hypothesized before (Goodwin and Henry, 1978; Duysens et al., 1985b). As in experimental observations (Duysens et al., 1985a), inhibition overlaps spatially with excitation in the model.

However, the cut-off at high-velocities in our model neurons is by a factor of two above that reported in real cells. The reason for this are complex. We eliminated this high cut-off in an earlier, numerically even more complex network model by introducing pair-pulse depression for all GABA synapses, which allowed us to increase the weight of the inhibition to the pyramidal neurons while keeping the input conductance change small in the null direction, thus making inhibition stronger at high velocities (Fig. 4 in Suarez et al., 1992).

In our model, DS persists down to low velocities $\left(0.33^{\circ} / \mathrm{sec}\right.$ here), as observed physiologically (Orban et al., 1981b; Orban, 1984; Duysens et al., 1987; Saul and Humphrey, 1992a). The model predicts that the ratio of the optimal spatial displacement for DS (Baker and Cynader, 1986) and the $\mathrm{GABA}_{\mathrm{B}}$ 's time constant should be approximately equal to the lowest direction-selective velocity. The optimal spatial displacement for DS corresponds approximately to the spatial displacement between pyramidal and smooth neurons $\left(5^{\prime}\right)$, a small fraction of the Gabor wavelength of a pyramidal neuron's receptive field profile $\left(24^{\prime}\right.$; see Suarez, 1995), as found in cortical neurons by Baker and Cynader (1986).

DS is relatively independent of velocity in velocity low-pass direction- selective neurons (Orban et al., 1981b; Duysens et al., 1987). In our model, rapid-onset inhibition mediated by $\mathrm{GABA}_{\mathrm{A}}$ contributes to DS above $2 \% \mathrm{sec}$, while persistent inhibition mediated by $\mathrm{GABA}_{\mathrm{B}}$ is exclusively responsible for DS at lower velocities (Fig. 9). Indeed, these differential roles of $\mathrm{GABA}_{\mathrm{A}}$ and $\mathrm{GABA}_{\mathrm{B}}$ in DS lead to specific model predictions. In past experiments (Sillito, 1975, 1977; Baumfalk and Albus, 1988), the influence of velocity has not been tested.

\section{Conclusions}

From the early days of Hubel and Wiesel (1962) until today (e.g., Carandini and Heeger, 1994), it has always been assumed that geniculate input provides the dominant excitatory drive to striate cortex. From an anatomical point of view, given the small number of geniculate synapses on spiny stellate cells, it could be argued that the geniculate input only provides a minor fraction of the excitatory input, the majority originating in neighboring and recurrently connected cortical cells. As we have shown here, such a network can reproduce a host of experimental results pertaining to direction-selective cortical simple cells. Furthermore, our model makes specific predictions that can be tested using current experimental techniques.

Our efforts represent but a starting point for explaining other receptive field properties of visual neurons, such as their orientation, disparity tuning, spatial or spatio-temporal separability, within the framework of massive recurrent excitation. Furthermore, a similar network architecture could also be used to explain receptive field properties in other sensory cortical areas. The high degree of cortical interconnectivity raises the possibility that receptive field properties are much less determined by proper wiring of the incoming geniculate input than by collective computation in cortical networks. If true, this would imply that such static concepts as the "center of the receptive field" or the "optimal orientation" might be to a considerable extent depen- 
dent on the exact stimulus arrangement and behavioral state of the animal (Allman et al., 1985; Gulyas et al., 1987; Gilbert and Wiesel, 1990; Press et al., 1994; Sillito et al., 1994).

\section{References}

Adelson EH, Bergen JR (1985) Spatiotemporal energy models for the perception of motion. J Opt Soc Am A 2:284-299.

Ahmed B, Anderson JC, Douglas RJ, Martin KAC, Nelson C (1994) Polyneuronal innervation of spiny stellate neurons in cat visual cortex. J Comp Neurol 341:39-49.

Albrecht DG, Geisler WS (1991) Motion selectivity and the contrastresponse function of simple cells in the visual cortex. Visual Neurosci 7:531-546.

Albrecht DG, Hamilton DB (1982) Striate cortex of monkey and cat: contrast- response function. J Neurophysiol 48:217-237.

Albus K (1980) The detection of movement direction and effects of contrast reversal in the cat's striate cortex. Visual Res 20:289-293.

Allman J, Miezin F, McGuiness E (1985) Stimulus specific responses from beyond the classical receptive field - neurophysiological mechanisms for local global comparisons in visual neurons. Annu Rev Neurosci 8:407-430.

Baker CL, Cynader MS (1986) Spatial receptive-field properties of direction-selective neurons in cat striate cortex. J Neurophysiol 55: 1136- 1152.

Barlow IIB, Levick WR (1965) The mechanism of directionally selective units in rabbit's retina. J Physiol (Lond) 178:477-504.

Baumfalk U, Albus K (1988) Phaclofen antagonizes baclofen-induced suppression of visually evoked responses in the cat's striate cortex. Brain Res 463:398-402.

Beaulieu C, Colonnier M (1983) The number of neurons in the different laminae of the binocular and monocular regions of area 17 in the cat. J Comp Neurol 231:180-189.

Benevento L, Creutzfeldt O, Kuhnt U (1972) Significance of intracortical inhibition in the visual cortex. Nature 238:124-126.

Berman NEJ, Wilkes ME, Payne BR (1987) Organization of orientation and direction selectivity in areas 17 and 18 of cat cerebral cortex. J Neurophysiol 58:676-699.

Berman NJ, Douglas RJ, Martin KAC, Whitteridge D (1991) Mechanisms of inhibition in cat visual cortex. J Physiol (Lond) 440:697722.

Berman NJ, Douglas RJ, Martin KAC (1992) GABA-mediated inhibition in the neural networks of visual cortex. In: Progress in brain research, Vol 90 (Mize RR, Marc RE, Sillito AM, eds), pp 443-476. New York: Elsevier.

Bernander O (1993) Synaptic integration and its control in neocortical pyramidal cells. Ph.D. thesis, California Institute of Technology.

Bernander O, Douglas R, Martin K, Koch C (1991) Synaptic background activity influences spatiotemporal integration in single pyramidal cells. Proc Natl Acad Sci USA 88:11569-11573.

Bernander O, Douglas RJ, Koch C (1994) Amplification and linearization of synaptic input to the apical dendrites of cortical pyramidal neurons. J Neurophysiol 72:2743-2753.

Bishop PO, Coombs JS, Henry GH (1971) Responses to visual contours: spatio- temporal aspects of excitation in the receptive fields of simple striate neurones. J Physiol (Lond) 219:625-657.

Bliss TVP, Collingridge GL (1993) A synaptic model of memory: long term potentiation in the hippocampus. Nature 361:31-39.

Braitenberg V, Schiiz A (1991) Anatomy of the cortex. Berlin: Springer.

Bullier J, Norton TN (1979) Comparison of receptive-field properties of $\mathrm{X}$ and $\mathrm{Y}$ ganglion cells with $\mathrm{X}$ and $\mathrm{Y}$ lateral geniculate cells in the cat. J Neurophysiol 42:274-291.

Busch C, Sakmann B (1990) Synaptic transmission in hippocampal neurons: numerical reconstruction of quantal IPSCs. Cold Spring Harbor Symp Quant Biol 55:69-80.

Bush PC, Douglas RJ (1991) Synchronization of bursting action potential discharges in a model network of neocortical neurons. Neural Comput 3:19-30.

Bush PC, Sejnowski TJ (1993) Reduced compartmental models of neocortical pyramidal cells. J Neurosci Methods 46:159-166.

Carandini M, Heeger DJ (1994) Summation and division by neurons in primate visual cortex. Science 264:1333 1335.

Cleland BG, Lee BB (1985) A comparison of visual responses of cat lateral geniculate nucleus neurones with those of ganglion cells afferent to them. J Physiol (Lond) 369:249-26.

Connors BW, Malenka RC, Silva LR (1988) Two inhibitory postsynaptic potentials, and GABA-A, and GABA-B receptor-mediated responses in neocortex of rat and cat. J Physiol (Lond) 406:443-468.

Creutzfeldt OD, Kuhnt U, Benevento LA (1974) An intracellular analysis of visual cortical neurones to moving stimuli: responses in a cooperative neuronal network. Exp Brain Res 21:251-274.

Dawis S, Shapley R, Kaplan E, Tranchina D (1984) The receptive field organization of X-cells in the cat: spatiotemporal coupling and asymmetry. Vision Res 24:549-564.

Dean AF (1980) The contrast dependence of direction selectivity. J Physiol (Lond) 303:38-39.

Dean AF (1981) The relationship between response amplitude and contrast for cat striate cortical neurons. J Physiol (Lond) 318:413-427.

DeAngelis GC, Ohzawa I, Freeman RD (1993) Spatiotemporal organization of simple-cell receptive fields in the cat's striate cortex. II. Linearity of temporal and spatial summation. J Neurophysiol 69 $1118-1135$.

Dehay C, Douglas RJ, Martin KAC, Nelson C (1991) Excitation by geniculocortical synapses is not 'vetoed' at the level of dendritic spines in cat visual cortex. J Physiol (Lond) 440:723-734.

Derrington AM, Fuchs AF (1979) Spatial and temporal properties of $\mathrm{x}$ and $\mathrm{y}$ cells in the cat lateral geniculate nucleus. $\mathrm{J}$ Physiol (Lond) 293:347-364.

Douglas RJ, Martin KAC (1990) Neocortex. In: The synaptic organization of the brain, 2nd edition (Shepherd GM, ed), pp 389-438. Oxford: Oxford UP.

Douglas RJ, Martin KAC (1991) A functional microcircuit for cat visual cortex. J Physiol (Lond) 440:735-769.

Douglas RJ, Martin KAC, Whitteridge D (1988) Selective responses of visual cortical cells do not depend on shunting inhibition. Nature 332:642-644.

Douglas RJ, Martin KAC, Whitteridge D (1991) An intracellular analysis of the visual responses of neurones in cat visual cortex. J Physiol (Lond) 440:659-696.

Douglas RJ, Koch C, Mahowald M, Martin KAC, Suarez HH (1995) Recurrent excitation in neocortical circuits. Science, in press.

Dreher B, Sanderson KJ (1973) Receptive field analysis: responses to moving visual contours by single lateral geniculate neurones in the cat. J Physiol (Lond) 234:95-118.

Duysens J, Orban G, Cremieux J (1985a) Velocity sensitivity in the cat visual system. Ii. Independence from interactions between different loci. J Neurophysiol 54:1050-1067.

Duysens J, Orban GA, Cremieux J, Maes H (1985b) Velocity selectivity in the cat visual system. III. Contribution of temporal factors. J Neurophysiol 54:1068-1083.

Duysens J, Maes H, Orban G (1987) The velocity dependence of direction selectivity of visual cortical neurones in the cat. $J$ Physiol (Lond) 387:95- 113

Edwards FA, Konnerth A, Sakmann B (1990) Quantal analysis of inhibitory synaptic transmission in the dentate gyrus of rat hippocampal slices: a patch-clamp study. J Physiol (Lond) 430:213-249.

Emerson RC, Bergen JR, Adelson EH (1992) Directionally selective complex cells and the computation of motion energy in cat visual system. Vision Res 32:203-218.

Emerson RC, Gerstein GL (1977) Simple striate neurons in the cat. II. Mechanisms underlying directional asymmetry and directional selectivity. J Neurophysiol 40:136-155.

Enroth-Cugell C, Robson JG, Schweitzer DE, Watson AB (1983) Spatio-temporal interactions in cat retinal ganglion cells showing linear spatial summation. J Physiol (Lond) 341:279-307.

Enroth-Cugell C, Robson JG (1966) The contrast sensitivity of retinal ganglion cells of the cat. J Physiol (Lond) 187:517-552.

Eysel UT, Muche T, Wörgötter F (1988) Lateral interactions at direction-selective striate neurones in the cat demonstrated by local cortical inactivation. J Physiol (Lond) 399:657-675.

Ferster D (1988) Spatially opponent excitation and inhibition in simple cells of the cat visual cortex. J Neurosci 8:1172-1180.

Ferster DL (1989) The synaptic inputs to simple cells of the cat visual cortex. In: Neural mechanisms of visual perception (Lam DMK, Gilbert CD, eds), pp 63-85.

Ferster D, Jagadeesh B (1992) EPSP-IPSP interactions in cat visual cortex studied with in vivo whole-cell patch recording. J Neurosci $12: 1262-1274$ 
Freund TF, Martin KAC, Somogyi P, Whitteridge D (1985a) Innervation of cat visual areas 17 and 18 by physiologically identified $X$ and Y-type afferents. II. Identification of postsynaptic targets by GABA immunocytochemistry and Golgi impregnation. J Comp Neurol 242:275-291.

Freund TF, Martin KAC, Whitteridge D (1985b) Innervation of cat visual areas 17 and 18 by physiologically identified $X$ - and Y-type afferents. I. Arborization patterns and quantitative distribution of postsynaptic elements. J Comp Neurol 242:263-274.

Frishman LJ, Schweitzer-Tong DE, Goldstein EB (1983) Velocity tuning of cells in dorsal lateral geniculate nucleus and retina of the cat. J Neurophysiol 50:1393-1414.

Gabbott PLA, Somogyi P (1986) Quantitative distribution of GABAimmunoreactive neurons in the visual cortex (area 17) of the cat. Exp Brain Res 61:323-331.

Gabbott PLA, Martin KAC, Whitteridge D (1987) Connections between pyramidal neurons in layer 5 of cat visual cortex (area 17). $J$ Comp Neurol 259:364-381.

Ganz L (1984) Visual cortical mechanisms responsible for direction selectivity. Vision Res 24:3-11.

Gilbert CD, Wiesel TN (1983) Clustered intrinsic connections in cat visual cortex. J Neurosci 3:1116-1133.

Gilbert CD, Wiesel TN (1990) The influence of contextual stimuli on the orientation selectivity of cells in primary visual cortex of the cat. Vision Res 30:1689-1701.

Gizzi MS, Katz E, Schumer RA, Movshon JA (1990) Selectivity for orientation and dircction of motion of single neurons in cat striate and extrastriate visual cortex. J Neurophysiol 63:1529-1543.

Goodwin AW, Henry GH (1978) The influence of stimulus velocity on the responses of single neurones in the striate cortex. J Physiol (Lond) $277: 467-482$.

Grieve KL, Sillito AM (1991) A re-appraisal of the role of layer vi of the visual cortex in the generation of cortical end inhibition. Exp Brain Res 87:521-529.

Gulyas B, Orban GA, Duysens J, Maes H (1987) The suppressive influence of moving textured backgrounds on responses of cat striate neurons to moving bars. J Physiol (Lond) 57:1767-1791

Gulyas B, Lagae L, Eysel U, Orban GA (1990) Corticofugal feedback influences the responses of geniculate neurons to moving stimuli. Exp Brain Res 79:441-446.

Hamilton DB, Albrecht DG, Geisler WS (1989) Visual cortical receptive fields in monkey and cat: spatial and temporal phase transfer function. Vision Res 29:1285-1308.

Hamos JE, Davis LD, Sterling P (1983) Four types of neuron in layer IVab of cat cortical area 17 accumulate 3 H-GABA. J Comp Neurol 217:449-457.

Heeger DJ (1993) Modeling simple-cell direction selectivity with normalized, half-squared, linear operators. J Neurophysiol 70:18851898.

Holub RA, Morton-Gibson M (1981) Response of visual cortical neurons of the cat to moving sinusoidal gratings: response-contrast functions and spatiotemporal interactions. J Neurophysiol 46:1244-1259.

Hubel DH, Wiesel TN (1962) Receptive fields, binocular interaction and functional architecture in the cat's visual cortex. J Physiol (Lond) 160:106- 154.

Ikeda H, Wright MJ (1975) Spatial and temporal properties of sustained and transient neurones in area 17 of the cat's visual cortex. Exp Brain Res 22:363-383.

Jagadeesh B, Wheat HS, Ferster D (1993) Linearity of summation of synaptic potentials underlying direction selectivity in simple cells of the cat visual cortex. Science 262:1901-1904.

Jones JP, Palmer LA (1987a) The two-dimensional spatial structure of simple receptive ficlds in cat striate cortex. J Neurophysiol 58:11871211.

Jones JP, Palmer LA (1987b) An evaluation of the two-dimensional gabor filter model of simple receptive fields in cat striate cortex. J Neurophysiol 58:1233-1258.

Kaplan E, Purpura K, Shapley R (1987) Contrast affects the transmission of visual information through the mammalian lateral geniculate nucleus. J Physiol (Lond) 391:267-288.

Koch C, Poggio T (1985) The synaptic veto mechanism: does it underlie direction and orientation selectivity in the visual cortex? In: Models of the visual cortex (Rose D, Dobson VG, eds), pp 408-419. New York: Wiley.

Koch C, Douglas R, Wehmeier U (1990) Visibility of synaptically induced conductance changes: theory and simulations of anatomically characterized cortical pyramidal cells. J Neurosci 10:1728-1744.

Kriegstein AR, LoTorco JJ (1990) Gabaergic synaptic currents in slices of neocortex analyzed with whole-cell and cell-detached patch-clamp techniques. Soc Neurosci Abstr 16:30.9.

LaCaille JC (1991) Postsynaptic potentials mediated by excitatory and inhibitory amino acids in interneurons of stratum pyramidale of the CA1 region of rat hippocampal slices in vitro. J Neurophysiol 66: 1441-1454.

Lee B, Willshaw D (1978) Responses of the various types of cat retinal ganglion cells to moving contours. Vision Res 18:757-765.

Lennie P (1980) Parallel visual pathways: a review. Vision Res 20: 561-594.

LeVay S (1986) Synaptic organization of claustral and geniculate afferents to the visual cortex of the cat. J Neurosci 6:3564-3575.

Li C, Creutzfeldt O (1984) The representation of contrast and other stimulus parameters by single neurons in area 17 of the cat. Pfluegers Arch 401:304-314.

Linsenmeier RA, Frishman LJ, Jakeila HG, Enroth-Cugell C (1982) Receptive field properties of $\mathrm{X}$ and $\mathrm{Y}$ cells in the cat retina derived from contrast sensitivity measurements. Vision Res 22:1173-1183.

Lytton WW, Sejnowski TJ (1991) Simulations of cortical pyramidal neurons synchronized by inhibitory interneurons. J Neurophysiol 66 : $1059-1079$.

Maex R (1994) Direction-selective simple cells in cat striate cortex: a modelling study. PhD thesis, Katholieke Universiteit et Leuven, Belgium.

Maex R, Orban GA (1991) Subtraction inhibition combined with a spiking threshold accounts for cortical direction selectivity. Proc Natl Acad Sci USA 88:3549-3553.

Maex R, Orban GA (1992) A model circuit for cortical temporal lowpass filtering. Neural Comput 4:932-945. Martin KAC (1984) Neuronal circuits in cat striate cortex. In: Cerebral cortex, Vol 2, Functional properties of cortical cells (Jones EG, Peters A, eds), pp 241284. New York: Plenum

Martin KAC, Somogyi P (1985) Local excitatory circuits in area 17 of the cat. In: Models of the visual cortex (Rose D, Dobson VG, eds), pp 504-513. Chichester: Wiley.

Martin KAC, Somogyi P, Whitteridge D (1983) Physiological and morphological properties of identified basket cells in the cat's visual cortex. Exp Brain Res 50:193-200.

Mason A, Nicoll A, Stratford K (1991) Synaptic transmission between individual pyramidal neurons of the rat visual cortex. J Neurosci 11: $72-84$.

Mastronarde DN (1987) Two classes of single-input x-cells in car lateral geniculate nucleus. I. receptive-field properties and classification of cells. J Neurophysiol 57:357-380.

McCormick DA, Connors BW, Lighthall JW, Prince DA (1985) Comparative electrophysiology of pyramidal and sparsely spiny stellate neurons of the neocortex. J Neurophysiol 54:782-806.

McLean J, Palmer L (1989) Contribution of linear spatiotemporal receptive field structure to velocity selectivity of simple cells in area 17 of cat. Vision Res 29:675-679.

McLean J, Palmer LA (1994) Organization of simple cell responses in the three-dimensional (3-1) frequency domain. Visual Neurosci 11: 295-306.

McLean J, Raab S, Palmer LA (1994) Contribution of linear mechanisms to the specification of local motion by simple cells in areas 17 and 18 of the cat. Visual Neurosci 11:271-294.

Miller KD (1992) Models of activity-dependent neural development Semin Neurosci 4:61-73.

Movshon JA, Thompson ID, Tolhurst DJ (1978) Spatial and temporal contrast sensitivity of neurones in areas 17 and 18 of the cat visual cortex. J Physiol (Lond) 283:101-120.

Nelson S, Toth L, Sheth B, Sur M (1994) Orientation selectivity of cortical neurons during intracellular blockade of inhibition. Science 265:774-777.

Ohzawa I, Sclar G, Freeman RD (1982) Contrast gain control in the cat visual cortex. Nature 298:266-268.

Orban GA (1984) Neuronal operations in the visual cortex. Berlin: Springer.

Orban GA, Kennedy H, Maes H (1981a) Response to movement of neurons in areas 17 and 18 of the cat: velocity sensitivity. J Neurophysiol 45:1043-1058.

Orban GA, Kennedy H, Maes H (1981b) Response to movement of 
neurons in areas 17 and 18 of the cat: direction selectivity. I Neurophysiol 45:1059-1073.

Orban G, Hoffmann KP, Duysens J (1985) Velocity selectivity in the cat visual system. I. Response of LGN cells to moving bar stimuli: a comparison with cortical areas 17 and 18. J Neurophysiol 54:10261049.

Orban GA, Kennedy H, Bullier J (1986) Velocity sensitivity and direction selectivity of neurons in areas V1 and V2 of the monkey: influence of eccentricity. J Neurophysiol 56:462-480.

Payne BR, Berman N, Murphy EH (1980) Organization of direction preferences in cat visual cortex. Brain Res 211:445-450.

Pei X, Volgushev M, Vidyasagar TR, Creutzfeldt OD (1991) Whole cell recording and conductance measurements in cat visual cortex invivo. Neuroreport 2:485-488.

Peichl L, Wässle H (1979) Size, scatter, and coverage of ganglion cell receptive ficld centres in the cat retina. J Physiol (Lond) 291:117141.

Peters A, Payne BR, Rudd J (1994) A numerical analysis of the geniculocortical input to striate cortex in the monkey. Cereb Cortex 4:215-229.

Peters A, Payne BR (1993) Numerical relationships between geniculocortical cell modules in cat primary visual cortex. Cereb Cortex 3:69-78.

Press WH, Teukolsky SA, Vetterling WT, Flannery BP (1992) Numerical recipes in $\mathrm{C}, 2 \mathrm{~d}$ ed. Cambridge: Cambridge UP.

Press WA, Knierim JJ, Van Essen DC (1994) Neuronal correlates of attention to texture patterns in macaque striate cortex. Soc Neurosci Abstr 20:349.10.

Rapp M, Yarom Y, Segev I (1992) The impact of parallel fiber background activity on the cable propertics of cercbcllar Purkinje cells. Neural Comput 4:518-533.

Reid RC, Soodak RE, Shapley RM (1987) Linear mechanisms of directional selectivity in simple cells of cat striate cortex. Proc Natl Acad Sci USA 84:8740-8744.

Reid RC, Soodak RE, Shapley RM (1991) Directional selectivity and spatiotemporal structure of receptive fields of simple cells in cat striata cortex. J Neurosci 66:505-529.

Rodieck RW (1965) Quantitative analysis of cat retinal ganglion cell response to visual stimuli. Vision Res 5:583-601.

Ruff PI, Rauschecker JP, Palm G (1987) A model of direction-selective simple cells in the visual cortex based on inhibition asymmetry. Biol Cybern 57:147-157.

LeVay CDG (1976) Laminar patterns of geniculo-cortical projection in the cat. Brain Res 113:1-19.

Saul AB, Humphrey AL (1990) Spatial and temporal response properties of lagged and nonlagged cells in cat lateral geniculate nucleus. J Neurophysiol 64:206-224.

Saul AB, Humphrey AL (1992a) Temporal-frequency tuning of direction selectivity in cat visual cortex. Visual Neurosci 8:365-372.

Saul AB, Humphrey AL (1992b) Evidence of input from laged cells in the lateral geniculate nucleus to simple cells in cortical area 17 of the cat. J Neurophysiol 64:206-224.

Schiller PH (1982) Central connections of the retinal ON and OFF pathways. Nature 297:580-583.

Schiller PH (1992) The ON and OFF channels of the visual system. Trends Neurosci 15:86-92.

Shapley R, Perry VH (1986) Cat and monkey retinal ganglion cells and their visual functional roles. Trends Ncurosci 9:229-235.

Sherk H, Horton JC (1984) Receptive field properties in the cat's area 17 in the absence of ON-center geniculate input. J Neurosci 4:381393.

Sherman SM (1985) Functional organization of the W-, X-, and Y-cell pathways in the cat: a review and hypothesis. Prog Psychobiol Physiol Psychol 11:233-314.
Sillito AM (1975) The contribution of inhibitory mechanisms to the receptive field properties of neurones in the striate cortex of the cortex of the cat. J Physiol (Lond) 250:305-329.

Sillito AM (1977) Inhibitory processes underlying the directional specificity of simple, complex and hypercomplex cells in the cat's visual cortex. J Physiol (Lond) 271:699-720.

Sillito AM, Grieve KL, Cudeiro J, Davis JN (1994) Spatial integration and response correlation in the central visual system of cat and monkey. Soc Neurosci Abstr 20:608.10.

Suarez HH (1995) Direction selectivity in primary visual cortex using massive intracortical connections. Ph.D. thesis, California Institute of Technology.

Suarez. HH, Koch C. Dourglas RJ (1992) A model of direction selectivity in visual cortex using massive intracortical connections. In: Computation and neural systems 92 (Eeckman F, ed), pp 201-205. Kluwer.

Tanaka K (1983) Cross-correlation analysis of geniculostriate neuronal relationships in cats. J Neurophysiol 49:1303-1318.

Thomson AM, Girdlestone D, West DC (1988) Voltage-dependent currents prolong single-axon postsynaptic potentials in layer III pyramidal neurons in rat neocortical slices. J Neurophysiol 60:1896-1907.

Tolhurst DJ, Dean AF (1991) Evaluation of a linear model of directional selectivity in simple cells of the cat's striate cortex. Visual Neurosci 6:421-428.

Tolhurst DJ, Dean AF, Thompson ID (1981a) The dependence of response amplitude and variance of cat visual cortical neurones on stimulus contrast. Exp Brain Res 41:414-419

Tolhurst DJ, Dean AF, Thompson ID (1981b) Preferred direction of movement as an element in the organization of cat visual cortex. Exp Brain Res 44:340-342.

Torre V, Poggio T (1978) A synaptic mechanism possibly underlying directional selectivity to motion. Proc R Soc Lond [Biol] 202:409416.

Victor JD (1987) The dynamics of the cat retinal X cell centre. J Physiol (Lond) 386:219-246.

Watson AB, Ahumada AJ (1985) Models of human visual-motion sensing. J Opt Soc Am 2:322-342.

Wehmeier U, Dong D, Koch C, van Essen D (1989) Modeling the visual system. In: Methods in neuronal modeling (Koch C, Segev I, eds), pp 335-359. Cambridge, MA: MIT Press.

White EL (1989) Cortical circuits: synaptic organization of the cerebral cortex - structure, function and theory. Boston: Birkhauser.

Williams SH, Johnston D (1991) Kinetic properties of two anatomically distinct excitatory synapses in hippocampal CA3 ncurons. J Neurophysiol 66:1010-1020.

Wilson MA, Bower JM (1989) The simulation of large-scale neural networks. In: Methods in neuronal modeling (Koch C, Segev I, eds), pp 291-333. Cambridge, MA: MIT Press.

Winfield DA, Gatter KC, Powell TPS (1980) An electron microscopic study of the types and proportions of neurons in the cortex of the motor and visual areas of the cat and rat. Brain 103:245-258.

Wolf W, Hicks TP, Albus K (1986) The contribution of gaba-mediated inhibitory mechanisms to visual response properties of neurons in the kitten's striate cortex. J Neurosci 6:2779-2795.

Wörgötter F, Holt G (1991) Spatiotemporal mechanisms in receptive fields of visual cortical simple cells: a model. J Neurophysiol 65: 494-510.

Wörgötter F, Koch C (1991) A detailed model of the primary visual pathway in the cat: comparison of afferent excitatory and intracortical inhibitory connection schemes for orientation selectivity. J Neurosci 11:1959-1979.

Wörgötter F, Niebur E, Koch C (1992) Generation of direction selectivity by isotropic intracortical connections. Neural Comput $4: 332$ 340. 